\title{
Review Article \\ Health Implications of Electromagnetic Fields, Mechanisms of Action, and Research Needs
}

\author{
Sarika Singh and Neeru Kapoor \\ Occupational Health Division, Defence Institute of Physiology \& Allied Sciences, DRDO, Lucknow Road, Timarpur, \\ Delhi 110054, India \\ Correspondence should be addressed to Neeru Kapoor; neerukapoor0260@yahoo.com
}

Received 21 May 2014; Revised 26 August 2014; Accepted 1 September 2014; Published 23 September 2014

Academic Editor: Byung-Cheon Lee

Copyright (C) 2014 S. Singh and N. Kapoor. This is an open access article distributed under the Creative Commons Attribution License, which permits unrestricted use, distribution, and reproduction in any medium, provided the original work is properly cited.

Electromagnetic fields (EMF) have been implicated to influence a range of bodily functions. Given their ubiquitous nature, widespread applications, and capability to produce deleterious effects, conclusive investigations of the health risks are critical. Accordingly, this paper has been constructed to weigh the bioeffects, possible biointeraction mechanisms, and research areas in bioelectromagnetics seeking immediate attention. The several gaps in the existing knowledge do not permit one to reach a concrete conclusion but possibility for harmful effects cannot be underestimated in absence of consistent findings and causal mechanisms. Several studies with appropriate methodologies reflect the capacity of electromagnetic radiations to cause adverse health effects and there are several credible mechanisms that can account for the observed effects. Hence, need of the hour is to activate comprehensive well-coordinated blind scientific investigations, overcoming all limitations and demerits of previous investigations especially replication studies to concretize the earlier findings. Furthermore, appropriate exposure assessment is crucial for identification of dose-response relation if any, and the elucidation of biological interaction mechanism. For the time being, the public should follow the precautionary principle and limit their exposure as much as possible.

\section{Introduction}

The terrestrial electromagnetic environment has been and is being rapidly altered by humans as a result of technological advancements. This was well recognised very early in the seventies by Dr. Robert O. Becker (twice nominated for Nobel Prize) who said "I have no doubt in my mind that, at the present time, the greatest polluting element in the earth's environment is the proliferation of electromagnetic fields (EMFs)." On one hand, these electromagnetic waves (EMW) provide immeasurable benefits; on the other hand, they may also create potential hazards through uncontrolled and excessive radiation emissions. There are various types of electromagnetic radiations (EMRs) and depending upon their frequency and wavelength they are categorized into different types. Broadly the EMFs are categorized into two groups, namely, extremely low frequency (ELF) EMF $(>3 \mathrm{~Hz}-$ $3 \mathrm{kHz}$ ) and radiofrequency radiation (RFR) EMF $(3 \mathrm{kHz}-$ $300 \mathrm{GHz}$ ). Scientific investigations concerning the interaction of EMF with living systems, especially its health effects, are increasing in number. There are arguments for both positive [1-3] and negative bioeffects [4-8]. However, the lack of sufficient knowledge on biological effects of the vast majority of frequencies even below the safety limit leads to several apprehensions [9-11]. The discussion is still ongoing especially regarding the contentious nonthermal effects. It is considered that the energy absorbed calculated in terms of specific absorption rate (SAR) [12] is too low to produce biological effects [13]. At the same time, several studies have demonstrated the influence of EMF by energies that are much lower than those capable of producing temperature changes in living tissues $[10,14]$. The cell physiology either in vitro [14] or in vivo [15] can be affected by these temperature-insensitive reactions. Whether this could result in pathological alterations in higher life forms is a matter of debate [16]. Despite the documentation of temperatureinsensitive biological effects, they have not been considered in the existing EMF safety standard; rather it is principally based on heating effect of EMF [17]. The current SAR values 
TABLE 1: Showing the SAR values for general public and occupational groups laid by ICNIRP [18], International Commission on Nonionising Radiation Protection; SAR stands for specific absorption rate expressed in Watts per kilogram (W/kg).

\begin{tabular}{|c|c|c|c|c|c|c|}
\hline \multirow[b]{2}{*}{ Frequency range } & \multicolumn{3}{|c|}{ General public } & \multicolumn{3}{|c|}{ Occupational exposure } \\
\hline & Whole body SAR & $\begin{array}{l}\text { Localized SAR-head } \\
\text { and trunk }\end{array}$ & $\begin{array}{l}\text { Localized } \\
\text { SAR-limbs }\end{array}$ & Whole body SAR & $\begin{array}{l}\text { Localized SAR-head } \\
\text { and trunk }\end{array}$ & $\begin{array}{l}\text { Localized } \\
\text { SAR-limbs }\end{array}$ \\
\hline $100 \mathrm{KHz}-10 \mathrm{MHz}$ & 0.08 & 2 & 4 & 0.4 & 10 & 20 \\
\hline $10 \mathrm{MHz}-10 \mathrm{GHz}$ & 0.08 & 2 & 4 & 0.4 & 10 & 20 \\
\hline
\end{tabular}

for general and occupational groups are presented in Table 1. As a result, current recommendations are established on the lowest exposure known to induce acute observable effects due to heating [7].

In the past, when much of the attention was centered on certain EMW called ionizing radiation, the others called nonionizing radiation (NIR) were generally assumed to be harmless. However, after World War II, this assumption has been reconsidered. The overwhelming scientific investigations concerning health effects of NIR have highlighted their potential to affect the well-being of biological organism. Several researchers have raised questions regarding adequacy of current safety limits [17] and asserted for their revival so that the new biologically based exposure limits will be capable of eliminating the possibility of bioeffects [19].

Some of the documented bioeffects include changes in melatonin levels [20-25], induction of heat shock protein (hsp) [26], effects on spatial memory [27, 28], alteration of intracellular calcium concentration [29], changes in bloodbrain-barrier permeability (BBB) [30], enzyme activity [31], genotoxicity $[32,33]$, nonspecific disabilities, and subjective symptoms [34-37] to name a few. Also, radiation exposure from mobile phones (MPs) has been linked with tinnitus, brain tumours, and acoustic neuroma [38-41]. Additionally, studies at cellular/molecular level are important in illuminating the actual primary injury produced by EMFs [17, 27].

The field of bioelectromagnetics is surrounded with controversies because some studies are contradictory [11, 42] and not always corroborated by independent researchers [35]. The lack of any accepted causal mechanism further adds to the controversy. As a result, important details are simply not comprehended and generate confusion in the general public. As uses expand, the new situations are likely to further increase the environmental EMF levels. To cope with these situations and to promote life of biological organisms more comfortably and efficiently achieving a scientific understanding of the biointeractions of these fields and evaluation of health risks is highly desirable. This paper, therefore, has been constructed to weigh carefully the bioeffects, biointeraction mechanisms and lacunae in EMF research areas seeking immediate attention so that the public is not excessively exposed nor the technological advancements suffer a setback by unjust fears that may or may not exist. In this review, we shall restrict our discussion to the health relevant effects of ELF-EMF and RFR-EMF.

ELF and RFR-EMF related studies were identified by peer-reviewed literature and data searched in electronic database (PubMed) using a number of key words and their combinations (electromagnetic field, health effects, electric, magnetic, reproductive outcome, and biointeraction mechanisms as examples) in order to find English-language reports related to electromagnetic field health effects and their probable modes of action. A number of papers were retrieved by hand searching several journals and few were obtained through direct correspondence with the authors. Unlike other review papers, no strict inclusion criteria were set. However, a rational explanation of the experimental design, use of control/sham population, exposure conditions, blinding of the research, statistical assessment of the data, and role of artifacts could be reached for most, but not all investigations.

\section{Health Effects of Electromagnetic Fields}

2.1. Electromagnetic Hypersensitivity (EHS). EHS is a recent phenomenon of occurrence of subjective signs and symptoms in some sensitive individuals with EMF experience from varied electronic sources. Despite lower levels of exposures, symptoms of ill health have been observed among the subjects [34]. According to WHO [43], about 1-3\% of the world's population are affected by this EHS syndrome. The exposure to EMFs especially at lower levels and for long duration was originally reported among the East European radar workers and linked with a number of subjective and objective (skin and mucosa-related) symptoms. Sufferers often label EHS as loner's disease because of the consequent social isolation [9]. Epidemiological investigations have been conducted on people complaining about unpleasant symptoms (Table 2). Complainants have related their symptoms most frequently to exposure to MP base stations (74\%) followed by MPs (36\%), cordless phones (29\%), and power lines (27\%) [36]. Objective skin symptoms of EHS have been related to increase in mast cell counts and their degranulation, thereby causing the release of inflammatory substances such as histamine responsible for allergic hypersensitivity, sensation of itch and pain, edema, local erythema, and many kinds of dermatoses [19]. With reference to effects of ELFEMF, Barsam et al. [44] studied the effect of occupational exposure on sleep quality in high voltage substation workers. In their case-control study, they found poor sleep quality among $90.5 \%$ of cases and $85.3 \%$ of controls. Despite, the increased prevalence of poor sleep quality in exposed group, no statistically significant difference was reached. Similar occupational studies conducted in substation units of a petroleum complex also revealed higher percentage of poor sleep quality in addition to poor health condition in 
TABLE 2: Subjective signs and symptoms of electromagnetic hypersensitivity (EHS) $[34,36]$.

\begin{tabular}{lccc}
\hline (1) Sleep disorders & (2) Headaches & (3) Palpitations & (4) Hot flushes \\
(5) Sweating & (6) Tinnitus & (7) Fatigue & (8) Dizziness \\
(9) Concentration difficulties & (10) Limb pain & (11) Heart disease & (12) Nervousness \\
(13) Arthropathy & (14) Skin rash & (15) Oculopathy & (16) Depression \\
(17) Back pain & (18) Tremor & (19) Nausea & (20) Loss of energy \\
(21) Circulatory disturbance & (22) Loss of appetite & (23) Breathing difficulties & \\
\hline
\end{tabular}

exposed population when compared to control population [45]. However, the researchers in this group also could not reach any statistically significant correlation between the ELF-EMF exposure level and poor quality of sleep and health status. Another case-control study undertaken on the occupational group of electric utility workers highlighted the increased rate of suicide attempts in exposed group as compared to controls [46]. The authors also suggested that the occurrence of depression in the exposed workers might be the plausible reason. A study by Beale et al. [47] demonstrated the occurrence of psychological symptoms like suicide, depression, and unmanageable emotional condition amongst the residents exposed to chronic $50 \mathrm{~Hz}$ MF exposure as a result of their residence in the vicinity of high-voltage substations and power transmission lines. Case studies and anecdotal reports in this regard indicate that people's health problems like diabetes, multiple sclerosis, asthma, and so forth could have some association with biologically active dirty electricity which has been found to improve when levels are reduced [48]. Dirty electricity present in the surroundings has been shown to affect the well-being of teachers and pupils. Use of filters ameliorated the effects, thereby protecting sensitive individuals [49].

As regards RFR-EMF, Navarro et al. [37] carried out a health survey in the vicinity of a cellular phone base station, working in DCS- $1800 \mathrm{MHz}$ frequency range with exposition time greater than 6 hours/day, 7 days/week, in 95\% of the subjects. Exposure assessment was done by measuring microwave power densities at residence of respondents. Statistical analysis revealed a significant correlation between the declared severity of symptoms and measured power density. The study also showed an increase in the declared severity in groups with higher exposures. Comparable studies have also been performed reporting significant relation of some symptoms to the measured exposures [34]. Epidemiological studies suggest that frequency and severity of symptoms tend to increase with duration of exposure and are reversible if exposure is discontinued temporarily or permanently with symptomatic and general supportive treatment and also severity weakens for those residing far away from exposure source. For instance, in one of the health surveys among self-declared EHS individuals, 90\% of subjects reported occurrence of health symptoms when present in the exposure area and disappearance of the same after leaving the exposure area [36]. Studies have also highlighted the significant link between longer duration of daily MP use and health effects $[31,50,51]$. The MP use by children in this regard can be deleterious as their nervous system is under development and greater amount of energy is absorbed because of their thinner skull bones as compared to adults; additionally longer exposure duration increases their vulnerability to a greater extent [52]. However, to date, quality double-blind studies have not shown any correlation between subjective health complaints and RF exposure [43]. At the same time, epidemiological studies of EMF well-being are difficult to conduct because of imprecision in exposure assessment [5356] and lack of objectivity in measuring health effects or complaints [35]. In addition, the symptoms are nonspecific and subjective, based on self-reporting, and hence difficult to prove clinically in absence of clear diagnostic criteria for the condition [57]. The subjective complaints of well-being also vary from individual to individual and are a function of several variables like age, sex, social status, anxiety, current health status and accompanying disease, and personality traits [35] as well as the fear generated due to awareness of adverse effects from EMF exposures [34]. Psychological stress may be one of the consequences of EHS in patients and incomplete understanding of pathophysiology of these complex symptoms in absence of any single biomarker so far recognized unique to EHS makes the diagnosis and medical treatment a complicate endeavour $[9,35]$. It has also been suggested that subjective symptoms could be the consequence of already prevailing psychiatric condition or stress response resulting from EMF health concerns instead of the exposure itself [43]. In today's modern world, when we cannot part away from electronic gadgets, the EMF experiences are real and practically unavoidable, resulting in disturbances, which could be devastating for a few afflicted individuals. In dearth of any visible causal mechanism and pathophysiological biomarker, its etiology is quite incomprehensible. The pain of EHS patients aggravates further, when the majority of population do not experience any symptom with EMF exposures. The increasing number of reports on EHS however warns us to take this research promptly and locate the biomarkers that could give some clue in ameliorating the problems of such individuals. More investigations are hence needed to completely delineate the pathophysiology of EHS along with the generation of clear diagnostic criteria to identify the problem and develop strategies to limit the suffering of afflicted individuals. Besides, investigations dissecting the relation between EHS manifestation in elderly, children, and diseased persons (like neurodegenerative diseases, mentally and genetically unstable conditions) with EMF experiences are crucial. The lacunae in human studies, with regard to 
exposure assessment, inclusion of suitable controls, and data collection, and so forth, need to be eliminated to reach fruitful insights. For the time being, individuals with EHS need to be supported by the family, society, and the government to lead a normal and respectable life.

2.2. Cytotoxic and Genotoxic Effects. DNA alteration is considered to instigate carcinogenesis $[8,58]$ and change in DNA or micronuclei $(\mathrm{MN})$ generation is an accepted indication for genotoxicity [59]. Different cell types and organisms have been reported to react differently to differing exposure characteristics $[26,32,60]$. Concerning this, Ivancsits and coworkers [61] have identified three responders (fibroblast and melanocytes from human, granulosa cells from rat) and three nonresponder cell types (lymphocytes, monocytes, and skeletal muscle cells from human) when exposed to intermittent ELF-EMF using alkaline and neutral comet assays. Delimaris et al. [62] examined the effect of pulsed $50 \mathrm{~Hz}$ EF on human lymphocytes and showed significant DNA damage in exposed group in comparison to controls. However, Scarfí et al. [58] could not detect any statistically significant genotoxic difference in human fibroblasts exposed to intermittent $50 \mathrm{~Hz}$ EMFs. A number of studies have demonstrated the potential of ELF-EMF to cause DNA damage [33, 63-66].

As regards RFR-EMF, d'Ambrosio and coworkers [67] have documented significant micronuclei occurrence with phase modulated RFR as against no effect by continuous wave (CW). Phillips et al. [68] observed reduced and increased $\mathrm{SSB}$, at least in some experiments at low and high SARs, respectively, with RF-EMF exposures as opposed to sham controls. Increased DNA damage was reported in human lens epithelial cells exposed to $1.8 \mathrm{GHz}$ at $3 \mathrm{~W} / \mathrm{kg}$ [69]. Similar findings were reached by Sun et al. [70] on the same cell types after two-hour exposure to $1.8 \mathrm{GHz}$ at SARs of 3 and $4 \mathrm{~W} / \mathrm{kg}$. DNA damage at $4 \mathrm{~W} / \mathrm{kg}$ was found to be irreversible. Studies on marine radar operators also registered significant increase in $\mathrm{MN}$ frequency and comet parameters of \% of DNA in tail and tail moment after EMF exposures [1]. A detailed summary of various studies have been tabulated (Table 3). The occurrence of aneuploidy is well acknowledged to enhance the risk of tumour. In this context, linear and SAR dependent aneuploidy rise for chromosome 17 detected by fluorescence in situ hybridization post RFR exposure further substantiates their carcinogenic potential [67]. Significant DNA damage occurred after EMF exposure [71], which decreased with free radical scavenger treatment suggesting free radical involvement in inducing damage [3, 33]. Ferreira et al. [72] found a significant increase in erythrocyte $\mathrm{MN}$ frequency in newborn pups from irradiated pregnant rats suggesting the genotoxic potential of EMF exposure. Some investigations have shown the genotoxic potential of EMFs only when coupled with some mutagen or carcinogenic or physical agents indicating their synergistic effect $[13,64]$. Cell-culture studies by Luukkonen and coworkers [73] conducted on human SH-SY5Y neuroblastoma cells to study the combined effect of CW-RF $(872 \mathrm{MHz})$ and global system for mobile communication (GSM) with menadione suggested that $872 \mathrm{MHz} \mathrm{CW}-\mathrm{RF}$ radiations at $5 \mathrm{~W} / \mathrm{kg}$ might enhance chemically induced reactive oxygen species (ROS) production and thus cause secondary DNA damage. At the same time, enhancement of chemically induced DNA damage observed in this study was associated only with the CW-RF; no effects were seen with GSM signal. Amid these positive effects, Lagroye and coworkers [8] did not find any alkali-labile DNA damage, DNA-DNA cross-links, and DNA-protein cross-links in mouse fibroblast cells exposed to continuous $2450 \mathrm{MHz}$ at $1.9 \mathrm{~W} / \mathrm{kg}$ for two hours implying their inability to produce genotoxic effects directly by damaging the DNA. Proteomic study on endothelial cell-lines showed the manifestation and phosphorylation of various, chiefly unidentified proteins with RF-EMF exposure [14]. Amid these proteins is Hsp 27, a biomarker for cellular stress. Variation in the expression of cellular stress marker Hsp 90 postirradiation suggests the complex cell defense mechanism and cell response to EMF [26]. EMF interaction with biological system is a very complex process and is a function of several biological, physical, and environmental factors. The exquisite sensitivity of biological systems to EMF experiences leads to intriguing results and regardless of scientific evidences accumulated so far, it is difficult to conclude about EMF toxic effects as the contradictory findings tangle the results confounding the true findings. The differences in experimental protocols in terms of frequency applied, modulation, intensity, investigated endpoints, cell type used, sample size, and so forth have also added to the controversy $[5,10,60]$. Evaluation of present data also becomes difficult due to relatively small number of replication studies because of want for funding. However, possibility of genetic hazard cannot be eliminated in view of conflicting scientific outcomes and lack of accepted causal mechanisms, as the confusion has been generated by some commercial groups in their own interest. Therefore, the need of the hour is to critically analyse the differences and similarities in study variables with greater emphasis with regard to biological systems used, exposure characteristics, study protocol used, findings, data interpretation, and conclusions drawn along with recognising the source of funding, rather than giving weight to the number of studies either observing or not observing an effect. Addition of statistically sound scientific investigations dissecting EMF biointeraction with respect to field direction, orientation, polarization, duration and time of exposure, and so forth needs to be elucidated to gain fruitful insights into cellular behaviours and their responses. However, this province seems of least interest in bioelectromagnetics research. Further investigations investigating the link between EMF exposures and the blue print, that is, the DNA of children, aged, and sick (neurodegenerative, genetic, or mental disease), are needed and will further substantiate the earlier findings. Given the inconspicuous nature of EMF health effects, even slight deviations in experimental protocols can head towards intriguing outcomes. Therefore, sound experimental designs with appropriate methodologies are critical in order to reach firm grounds. In light of the researches done so far, we conclude that the bulk of literature on EMF and cytogenetic endpoints reflect both positive as well as negative effects. Hence, for now, precautions should be taken to limit the exposures as much as possible. 
2.3. EMF and Cancer. Epidemiological investigations have focused attention towards association between ELF-EMF exposures and incidence of tumours [6, 40, 41, 77]. Investigations concerning military personnel also indicate the development of tumours [17]. Amongst all cancer endpoints weighed in epidemiological investigations, childhood leukemia in connection to postnatal exposure exceeding $0.4 \mu \mathrm{T}$ gets the maximum support for an association [54]. Recently, a formal assessment for suggestion of carcinogenesis from exposure to static and ELF fields by the International Agency for Research on Cancer [78] concluded that ELF-MFs are possibly carcinogenic to humans and grouped them in $2 \mathrm{~B}$ category.

With regard to RFR-EMF, Hardell et al. [38] in their study suggested that occurrence of vestibular schwannoma has increased in the decades after introduction of cell phones in Sweden, the country with the highest use of mobile technology [17]. Hardell et al. [38] conducted a cross-sectional study in order to find the association between cell phone usage and vestibular schwannoma. Self-administered questionnaire was used for exposure and symptom assessment. Cases were identified from the Swedish cancer registries with age, sex, and geographical area matched control. Histopathological and anatomical tumour localization was done by CT and MRI scans. The authors reported risks for vestibular schwannoma among cell phone users. Significant rise in risk was reached for analogue phone users. Elevated risks were also calculated for cordless and digital phones but these results could not reach statistical significance. The researchers also reported cases of unilateral tinnitus in some persons using cell phone on ipsilateral side; however, a causal relation could not be established on the basis of case report. With regard to association between vestibular schwannoma and cordless and cellular phones, another interesting finding was observed. The highest rising incidence was obtained for men and the age group of 50-59 years. MP use has also been associated with ipsilateral cerebral brain tumours [77, 79], astrocytoma and acoustic neuroma [40,41], and contralateral temporal tumours [79]. Muscat et al. [79] evaluated the risk of brain tumour in relation to handheld cellular phone use. They included the malignant brain tumour patients as cases (469) and hospital patients as controls (422) after matching for gender, age, race, hospital, and month of admission. Structured interview was employed to gain information related to MP use. The mean duration of MP usage for cases and controls was found to be 2.8 years and 2.7 years, respectively. Out of the 41 measurable tumours, 26 appeared on the ipsilateral side while 15 appeared on the contralateral side. The authors did not find any association between short-term handheld cellular phone use and cerebral brain tumour risk. Another study by the same group [80] based on hospital derived acoustic neuroma patients as cases (90) and patients with nonmalignant diseases as controls (86) reported an average cell phone use of 4.1 and 2.2 years, respectively. Odds ratio was found to increase from 0.5 for 1-2 years cell phone use to 1.7 for 3-6 years group; however, the relative risk did not differ significantly with regard to the frequency, duration, and lifetime hours of use. The study by Muscat group was surrounded with limitations like lack of data on long-term users especially with regard to under-estimation of risks for slow growing tumours. Hepworth et al. [81] found no association between increased glioma risk and MP use along with absence of any relation with time since first use, years of use, total hours of use, or number of phone calls. The positive association observed between glioma risk and ipsilateral MP use in conjunction with the negative association as regards contralateral MP use was attributed to recall bias as the glioma patients tend to overreport the use on the same side of the tumour while under mentioning the same on the opposed side. This large case-control study was carried out with cases identified from hospital records and cancer registries whereas controls were selected randomly from the general practitioner's list after matching and personal contact. The details regarding the tumour site and laterality and tumour grade were judged from the pathology reports and scans. Computer assisted personal interviews were used to extract the details pertaining to MP use, number of calls made and received, start and stop year, side of use, model and make of MP used, network operator, use of handsfree, usage in rural/urban area, and so forth. On the basis of two case-control studies on brain tumours with regard to MP and cordless phone use, the Hardell group found an elevated risk for ipsilateral exposure with $>10$ years latency period and subjects started using MP and cordless phone below 20 years of age as regards both astrocytoma and acoustic neuroma [41]. Questionnaire method was employed to evaluate the exposures and cases were identified from the cancer registries. The tumour was assessed with regard to the anatomical region in the brain and was associated with the head side used during phone calls with ipsilateral use defined as greater than $50 \%$ and contralateral as less than $50 \%$ of the calling time. A review was undertaken with an aim to assess the brain tumour risk in relation to long-term use of mobile phones greater than 10 years and ipsilateral exposure [40]. The reviewers based their findings on the basis of 18 studies ( 2 cohort and 16 case-control) and found an increased risk for acoustic neuroma and glioma. In addition, the chance of tumour was found to be the highest for ipsilateral exposure in all the studies as reflected by the increased odds ratio. Another review by Levis et al. [82] concluded that the risk for head tumours doubles with longterm MP use. They also observed that methodological flaws with regard to nonblinding of experiments produce negative results and underestimate the risk for tumour development, whereas those studies, which are free from errors, biases, and financial interests, therefore, employing blind protocols, yield positive results indicating a cause-effect link between log-term use of MPs and statistically significant rise in head tumour risk. With increasing number of dynamic MP users worldwide, scientists consider this as the "largest biophysical human experimentation" ever conducted in the past history [17]. An interesting finding was reached in which incidence of brain tumour was found to be higher in populations of cell phone users in rural areas as compared to urban [39]. Also, average exposures have been observed to be slightly higher in rural areas compared to urban areas from MP base stations [34]. In this regard, the connection between exposures and geographic area, ethnicity, nutritional status, 
TABLE 3: Studies on the cytotoxic and genotoxic effects of electromagnetic fields.

\begin{tabular}{|c|c|c|c|c|}
\hline EMF characteristics & Study group & Method & Study outcome & Reference \\
\hline $\begin{array}{l}7 \mathrm{mT} 50 \mathrm{~Hz} \mathrm{MF} \text { for } 3 \mathrm{~h} \text {, ferrous } \\
\text { chloride }\left(\mathrm{FeCl}_{2}, 10 \mu \mathrm{g} / \mathrm{mL}\right) \text {, } \\
\text { melatonin }(0.5 \text { or } 1.0 \mathrm{mM})\end{array}$ & $\begin{array}{l}\text { Rat peripheral blood } \\
\text { lymphocytes }\end{array}$ & Alkaline comet assay & $\begin{array}{l}\text { Significant DNA damage only } \\
\text { after simultaneous exposure to } \\
\mathrm{FeCl}_{2} \text { and } \mathrm{MF} \text {, melatonin } \\
\text { ameliorates the effect. }\end{array}$ & {$[64]$} \\
\hline $\begin{array}{l}1.748 \mathrm{GHz} \text {, either } \\
\mathrm{CW} \text { or phase only modulated } \\
\text { wave } \mathrm{GMSK}^{*} \text { for } 15 \mathrm{~min} \text {. } \\
\text { Maximum SAR }=5 \mathrm{~W} / \mathrm{kg}\end{array}$ & $\begin{array}{l}\text { Human peripheral blood } \\
\text { lymphocytes cultures }\end{array}$ & $\begin{array}{l}\text { Cytokinesis block MN Assay } \\
\text { and proliferation index }\end{array}$ & $\begin{array}{l}\text { Statistically significant rise in } \\
\text { MN frequency following } \\
\text { exposure to phase modulated } \\
\text { wave. }\end{array}$ & {$[67]$} \\
\hline $\begin{array}{l}60 \mathrm{~Hz} \mathrm{MF} \text { at } 0.01 \mathrm{mT} \text { for } 24 \mathrm{~h} \\
\text { and } 48 \mathrm{~h}\end{array}$ & Male Sprague Dawley rats & $\begin{array}{l}\text { Microgel electrophoresis } \\
\text { assay }\end{array}$ & $\begin{array}{l}\text { Significantly increased single } \\
\text { and double DNA strand } \\
\text { breaks, prolonged 48-hour } \\
\text { exposure resulted in a larger } \\
\text { increase. }\end{array}$ & [33] \\
\hline $\begin{array}{l}\text { 847.74 MHz } \mathrm{CDMA}^{\dagger} \text {, } \\
\text { 835.62 } \mathrm{MHz}^{\circ} \mathrm{FMA}^{\ddagger} \text {, } \\
\text { 813.56 MHz iDEN } \$ 836.55 \\
\text { TDMA }^{\S}, 24 \mathrm{~h}\end{array}$ & Molt-4 T lymphoblastoid cells & $\begin{array}{l}\text { Single cell gel electrophoresis } \\
\text { and annexin V affinity assay }\end{array}$ & $\begin{array}{l}\text { No DNA damage or apoptosis } \\
\text { at any frequency, modulation } \\
\text { or exposure time. }\end{array}$ & {$[7]$} \\
\hline $\begin{array}{l}\text { MW frequency ranging from } \\
800 \text { to } 2000 \mathrm{MHz} \text {. }\end{array}$ & $\begin{array}{l}\text { MP users and age, sex } \\
\text { matched controls }\end{array}$ & Comet assay \& MN assay & $\begin{array}{l}\text { Significantly elevated comet } \\
\text { tail lengths and MN frequency } \\
\text { in MP users }\end{array}$ & {$[74]$} \\
\hline $\begin{array}{l}980,950 \mathrm{MHz}, 200 \mathrm{KHz} \\
\text { modulation, } \\
5 \mathrm{w} \text { and } 500 \mathrm{ppm} \text { toluene } \\
\text { applied for two weeks. }\end{array}$ & $\begin{array}{l}\text { Male bulb/c } \\
\text { mice }\end{array}$ & MN assay on lymphocytes & $\begin{array}{l}\text { MW radiation in } \\
\text { combination with toluene } \\
\text { produced significant } \\
\text { cytogenetic effects but not } \\
\text { alone }\end{array}$ & {$[13]$} \\
\hline $\begin{array}{l}\mathrm{UHF}^{\mathrm{Il}} \text {-EMF }(600 \mathrm{mWpeak} \\
834 \mathrm{MHz} ; 26.8-40 \mathrm{~V} / \mathrm{m} \text {; } \\
\text { vertical polarization) } \\
\text { Irradiation from } 5.30 \mathrm{pm} \text { to } \\
2.00 \text { am for } 8.30 \mathrm{~h} / \text { day, since } \\
\text { day of sperm detection until } \\
\text { offspring birth. }\end{array}$ & $\begin{array}{l}\text { Adult pregnant } \\
\text { Wistar rats only for irradiation } \\
\text { and their offspring for study }\end{array}$ & $\begin{array}{l}\text { MN assay, activity of } \\
\text { antioxidant enzymes, } \\
\text { quantified total sulfhydryl } \\
\text { content, protein carbonyl, } \\
\text { thiobarbituric acid reactive } \\
\text { species, and total } \\
\text { nonenzymatic antioxidant } \\
\text { defense }\end{array}$ & $\begin{array}{l}\text { Significant rise in } \mathrm{MN} \\
\text { frequency, no difference in } \\
\text { oxidative stress parameters in } \\
\text { offspring blood and liver }\end{array}$ & {$[72]$} \\
\hline RF-EMF, SAR $=1.3 \mathrm{~W} / \mathrm{kg}$ & $\begin{array}{l}\text { Small area of fore arm's skin in } \\
10 \text { female volunteers }\end{array}$ & $\begin{array}{l}\text { Collection of punch biopsies } \\
\text { from exposed and } \\
\text { nonexposed areas of skin. } \\
\text { Protein extraction by 2-DE } \\
\text { and protein expression } \\
\text { changes analyzed using } \\
\text { PDQuest software. }\end{array}$ & $\begin{array}{l}\text { Radiation exposures from } \\
\text { MPs have also been suggested } \\
\text { to affect protein expression in } \\
\text { human skin samples }\end{array}$ & {$[75]$} \\
\hline MP radiation & $85 \mathrm{MP}$ users and 24 nonusers & $\begin{array}{l}\text { MN assay on buccal mucosa } \\
\text { epithelial cells }\end{array}$ & $\begin{array}{l}\text { Significant rise in } \mathrm{MN} \\
\text { frequency and positive } \\
\text { correlation with duration of } \\
\text { use }\end{array}$ & [76] \\
\hline $\begin{array}{l}915 \mathrm{MHz}, 1 \mathrm{~h} / \text { day for } 2 \text { weeks } \\
\text { at } 2.4 \mathrm{~W} / \mathrm{m}^{2}, \text { whole body } \\
\text { average SAR- } 0.6 \mathrm{~W} / \mathrm{kg}\end{array}$ & Wistar rats & $\begin{array}{l}\text { Detection of DNA alteration } \\
\text { in peripheral leukocytes by } \\
\text { standard and } \mathrm{Fpg}^{\#} \text { modified } \\
\text { comet assay }\end{array}$ & $\begin{array}{l}\text { Oxidative stress could be the } \\
\text { likely cause of increased DNA } \\
\text { damage in exposed group }\end{array}$ & {$[71]$} \\
\hline $\begin{array}{l}2.45 \mathrm{GHz}, 2 \mathrm{~h} / \text { day for } 35 \text { days } \\
\text { to } 0.34 \mathrm{~mW} / \mathrm{cm}^{2} \text { power } \\
\text { density, whole body } \mathrm{SAR}= \\
0.11 \mathrm{~W} / \mathrm{Kg} \text {. }\end{array}$ & $\begin{array}{l}\text { Male wistar rats, control and } \\
\text { exposed group }\end{array}$ & $\begin{array}{l}\text { Double strand DNA damage } \\
\text { by microgel electrophoresis, } \\
\text { antioxidant enzymes, and } \\
\text { histone kinase estimation in } \\
\text { brain cells }\end{array}$ & $\begin{array}{l}\text { Significant elevation in comet } \\
\text { head, tail length, and tail } \\
\text { movement, decrease in } \mathrm{GPx}^{1} \text {, } \\
\mathrm{SOD}^{2} \text {, and histone kinase, and } \\
\text { increase in catalase }\end{array}$ & {$[31]$} \\
\hline
\end{tabular}


TABLE 3: Continued.

\begin{tabular}{|c|c|c|c|c|}
\hline EMF characteristics & Study group & Method & Study outcome & Reference \\
\hline $\begin{array}{l}\text { Pulsed MW from } 3 \mathrm{GHz} \text {, } \\
\text { 5.5 GHz and } 9.4 \mathrm{GHz} \text { Marine } \\
\text { RADAR }\end{array}$ & Marine RADAR operators & $\begin{array}{l}\text { Comet assay, } \mathrm{MN} \text { assay, } \mathrm{GSH}^{3} \text {, } \\
\text { and } \mathrm{MDA}^{4} \text { estimation }\end{array}$ & $\begin{array}{l}\text { Significant changes found in } \\
\text { comet and MN assay } \\
\text { parameters indicating } \\
\text { cytogenetic disruptions with } \\
\text { dropped GSH levels and } \\
\text { increased MDA levels in } \\
\text { exposed groups }\end{array}$ & {$[1]$} \\
\hline
\end{tabular}

economic status, and so forth may provide some remarkable insights and further enhance our understanding. However, association between brain cancer incidence and MP use remains unclear due to inconsistent findings. Short-term and long-term cellular telephone use also did not reflect any connection with cancer risk [6]. As far as cancer risk in animals is concerned, lymphoma risk was found to be significantly higher in experimental groups of mice exposed to pulsed RFR $900 \mathrm{MHz}$ coming from cellular phone than in controls [83].

Study by Cho and Chung [59] suggested the role of low density ELF-EMF as an enhancer in initiation process of Benzopyrene rather than as an initiator of mutagenic effects in human lymphocytes. Most reviews, however, do not support EMF exposures to be carcinogenic. Lack of supportive animal data for carcinogenic potential of EMF also makes the understanding of epidemiological outcomes a difficult enterprise along with faults in human experiments especially with respect to exposure assessment. Majority of the reviews have indicated lack of evidence for cancer initiation by magnetic field (MF) alone; however, accumulating evidence suggests that they could act as cocarcinogens if given in combination with known genotoxic or nongenotoxic carcinogens showing their synergistic effect. Additionally, the DNA damaging potential of EMFs by free radical generation and also by increasing their lifespan coupled with alterations in DNA repair mechanisms is of concern. However, considering the information in hand on carcinogenesis, cocarcinogenesis with tangling results in the absence of established mechanisms, strict limitations to exposures are suggested till the time any firm conclusion is reached.

2.4. Effects on Endocrine System. Among the several hormones secreted by the body, melatonin gained the focus of most of the EMF investigations. Melatonin, essentially a tryptophan derivative produced chiefly from the pineal gland has been documented to be affected by EMF in animals $[25,84,85]$ as well as in humans $[21,22,24]$. In addition, the enzyme machinery involved in melatonin biosynthesis has also been reported to be affected by EMF action $[86,87]$. Recently, Bellieni et al. [88] investigated the effect of ELFEMFs from incubators on melatonin production in newborns who had been kept in the incubators for at least 48 hours.
In their study, they found a transitory rise in melatonin secretion almost immediately after the babies were taken out from the incubators, highlighting the EMF potential to influence newborn melatonin production. Significant melatonin depression was registered in an occupational cluster of electronic equipment repairers exposed to ELF-EMFs due to their work in comparison to controls [89]. Epidemiological studies performed on Swiss railway workers exposed to $16.7 \mathrm{~Hz}$ MFs exhibited statistically significant reductions in mean evening 6-OHMS (6-hydroxymelatonin sulphate) concentrations after first and fifth days of exposure [24]. The result of yet another occupational study conducted among male electric utility workers exposed to $60 \mathrm{~Hz}$ yielded a decrease in postwork shift 6-OHMS/creatinine excretion with temporally stable MF exposures [21]. However, the reduction was found on second and third days of exposure whereas no change was observed on the very first day as opposed to that by Pfluger and Minder [24] indicating the role of exposure duration and that exposure effect may be delayed by several days. Anyway, the experiment of Wood et al. [22] suggested that exposure of humans to $50 \mathrm{~Hz}$ circularly polarized $20 \mu \mathrm{T}$ MF result in a delay in the onset of rise of plasma melatonin concentrations. As regards animal studies, Kumlin et al. [20] found an interesting augmenting effect on the circadian rhythm of melatonin synthesis in female mice strain $\left(\mathrm{CD}_{2} \mathrm{~F}_{1}\right)$ exposed to $50 \mathrm{~Hz} \mathrm{MF}$ having no or very low natural melatonin rhythm in contrast to previous researches using rodents showing chiefly diminishing effects. The findings do not corroborate the registered melatonin diminution in MF-exposed animals but do imply MF effects on pineal gland. Another experiment showed striking reduction in night-time melatonin concentrations as a result of exposure to rapid on/off mode MFs during the day for several days [25]. The authors pointed that rapidly changing exposure conditions create difficulties in acclimatization as opposed to stable exposure characteristics. The inadequacy in exposure characterization and the conduct of investigation at different times, for different exposure durations and at different locations, render the comparison among studies complicated [87]. Melatonin is highly accepted for its antioxidant and tumour inhibiting properties; hence, if oxidative stress (OS) is accompanied by suppression of melatonin levels, it may produce deleterious effects [87]. Given the importance of melatonin for organisms, further 
studies with better EMF characterization and standardization are crucial. Hormone serotonin, a tryptophan derivative produced chiefly from the pineal gland, has also been documented to be affected by EMF $[85,90]$. However, there are very few studies investigating serotonin and EMF connection. Serum cortisol and ACTH concentrations were found to rise significantly in male guinea pigs exposed to $50 \mathrm{~Hz}$ EMF reflecting the capacity to cause stress regardless of being a low frequency [91]. Noticeable depression in melatonin and corticosterone levels were reached in a study investigating the effect of continuous EMF emission from video display units in exposed embryos and young chickens [92]. In addition, significant rise in fetal loss was also registered indicating the adverse effects of these EMF emissions. Occupational studies focused on the effect of EMFs released from magnetostrictive cavitrons used by dentists showed serum cortisol diminution [93]. In the midst of all these studies reporting either an increase or decrease in cortisol concentration, another group of researchers reported no significant change [94] reflecting the inconsistency in this field. With regard to adrenaline and noradrenaline level, significant suppression was registered in electric utility workers exposed occupationally to $50 / 60 \mathrm{~Hz}$ EMFs [95].

As regards RFR, $900 \mathrm{MHz}$ with $217 \mathrm{~Hz}$ pulse frequency from digital wireless communication was reported to have no significant effect on salivary melatonin in healthy male students [96]. Cortisol which is a steroid hormone and one of the key stress biomarkers released from adrenal glands has been shown to be affected by RFR-EMF experience [96-99]. It is assumed that RFR-EMF may act as a stressor evident from the increased cortisol concentration documented in previous investigations with animals $[100,101]$ and humans [102-104]. However, the reports of cortisol increase are contradicted by the results of cortisol diminution $[97,98]$ and investigations reflecting no effect on adrenal cortisol secretion $[96,105]$ highlighting the disagreement in this field of investigation. Given the relevance of cortisol, any imbalance can lead to health impairments in due course [103]. More studies therefore in this connection are required to assess the course of action of the biological system in response to EMF stress. ACTH levels were reported to decrease [98] as well as not being affected [97] by RFR exposure. Significantly, higher levels of the stress biomarkers adrenaline and noradrenaline have been reported in physiotherapists [103]. Buchner and Eger [106] also assessed the catecholamines in subjects exposed to cell phone base station. They examined the acute as well as chronic effects of EMF exposure and found a significant increase in adrenaline and noradrenaline levels after EMF exposure, following a drop, but the normal levels were not restored even at the end of the study (about one and a half year). They also observed significant diminution in dopamine levels. Given the role of these catecholamines in controlling B.P., heart rate (HR), and other biological functions, the shift from baseline values due to stress has immense significance for health and well-being and, hence, their continual alteration may prove harmful in due course. Decreases in testosterone concentration with EMF exposure have been stated by some research groups $[98,105,107]$ with no effect as well in some reports [97]. FSH levels have also been found to reduce with EMF exposure at MP frequency [105]. So far as, effect on female reproductive hormones is concerned, there is limited number of studies. The few investigations on RFR from MPs and base stations have shown to mutate prolactin but not progesterone levels indicating the consequent effects on menstruation and pregnancy [98]. Significant rise in serum progesterone concentration has also been reported in pregnant rats after microwave exposure [108]. In addition, parallel studies investigating prolactin levels have documented normal levels even after exposure to radio-cellular phones $[97,109]$. As far as thyroid hormones are concerned, decrease in T3 $[98,100]$ and T4 $[98,110]$ and increase in T4 [100] in parallel to no effect or retention of normal T3 levels [110] have all been documented with EMF contact. These findings when taken together reflect the variation in EMF research and puzzle the understanding about EMF biointeraction and therefore urge for more studies. In light of the above evidences, it seems that EMF acts as a stressor and has the potential to affect the various endocrine secretions posing a significant health threat.

\subsection{Effects on Cardiovascular System. An experiment on} human head exposure to $37 \mathrm{~Hz}$ EMF at a flux density of $80 \mu \mathrm{T}$ suggested that EMF could alter nociception and may be associated with cardiovascular abnormalities [111]. Håkansson et al. [112] indicated a low level rise in AMI risk in the highest exposure group and observed by means of the synergy index of 2.7 in monozygotic twins that the genetically predisposed subjects have an increased EMF influence for AMI, possibly induced by reduced heart rate variability (HRV). A cohort study on electric utility workers pointed towards an association between occupational $50 \mathrm{~Hz}$ ELF-EMF exposure and arrhythmia related heart disorders [113]. On the contrary, a cohort study of railway workers exposed to $16.7 \mathrm{~Hz}$ intermittent MF indicated no association with fatality from arrhythmia related heart diseases or acute myocardial infarction (AMI) [4]. Because of the electric character, the circulatory and the nervous system particularly the autonomic nervous system is vulnerable to EMF effects [114]. More explicit damage of neurovegetative regulation, especially a decreased parasympathetic function, may result with high-intensity EMFs leading to cardiovascular malfunctioning [115]. ELF-EMFs have been also implicated to affect the HRV in newborns [116] and interfere with electronic medical equipment like implanted pace makers, but only when kept close to chest [117]. The detailed summary of various investigations concerning cardiovascular system effects have been listed (Table 4). Ali et al. [118] has attributed the alterations in rat heart functions as a result of decreased RBC membrane elasticity, permeability, and changes in molecular structure of haemoglobin exposed to $50 \mathrm{~Hz}, 0.2 \mathrm{mT}$ MFs. Yet another study on rats linked the observed histopathological alterations like unclear cytoplasm, polymorphic nucleus, disrupted fibrous tissue, necrosis, and bleeding in heart epithelial tissue with $50 \mathrm{~Hz}$ EMF exposure [119].

As regards RFR-EMF, Bortkiewicz et al. [115] found more impairment in 24-hour and resting ECG in AM (amplitude modulation) broadcast station workers when compared to radio-link station workers who are supposed to have less 
TABLE 4: Studies concerning the effects of electromagnetic fields on the cardiovascular system.

\begin{tabular}{|c|c|c|c|c|}
\hline EMF characteristic & Study group & Method & Study outcome & Reference \\
\hline Medium frequency EMF & $\begin{array}{l}\text { MF broadcast and radio link } \\
\text { station workers }\end{array}$ & $\begin{array}{l}\text { General medical examination, } \\
\text { cardiological, and family } \\
\text { history survey, } 24-\mathrm{hr} \mathrm{ECG}^{*} \text {, } \\
\mathrm{LVP}^{\dagger}, \mathrm{HRV} \text {, and } \mathrm{ABP}^{\ddagger} \\
\text { measurement }\end{array}$ & $\begin{array}{l}\text { EMF exposure is linked to } \\
\text { abnormalities in the } \\
\text { neurovegetative regulation of } \\
\text { cardiac function }\end{array}$ & {$[120]$} \\
\hline EMF exposure from MP & & & $\begin{array}{l}\text { Interference with medical } \\
\text { equipment like implanted } \\
\text { pacemakers }\end{array}$ & [117] \\
\hline MF exposure & Electric utility workers & $\begin{array}{l}\text { Cohort study } \\
\text { Cause of death from death } \\
\text { certificates }\end{array}$ & $\begin{array}{l}\text { Association between elevated } \\
\text { MF exposure in electric utility } \\
\text { jobs and mortality from } \\
\text { arrhythmia related causes }\end{array}$ & {$[113]$} \\
\hline $\begin{array}{l}50 \mathrm{~Hz}, 0.2 \mathrm{mT} \mathrm{MF} \text { for } 15 \text { and } 30 \\
\text { days }\end{array}$ & Male albino rats & $\begin{array}{l}\text { ECG, osmotic fragility, shape } \\
\text { of } \mathrm{RBCs}^{\text {, }} \text { membrane and } \mathrm{Hb}^{\S} \\
\text { structure tests, dielectric } \\
\text { relaxation of } \mathrm{Hb} \text { molecules } \\
\text { measured }\end{array}$ & $\begin{array}{l}\text { Alterations in ECG, RBCs } \\
\text { membrane elasticity and } \\
\text { permeability and changes in } \\
\text { molecular structure of } \mathrm{Hb} \text {. }\end{array}$ & {$[118]$} \\
\hline $\begin{array}{l}\mathrm{BC}^{\| l} 6-25 \mathrm{MHz} \text { and TV stations: } \\
66-900 \mathrm{MHz}\end{array}$ & $\begin{array}{l}\mathrm{BC}, \mathrm{TV} \text {, and radio relay } \\
\text { station operators }\end{array}$ & $\begin{array}{l}\text { Arterial pressure, lipid profile, } \\
\text { BMI, waist/hip ratio, smoking } \\
\text { habits, and family history for } \\
\text { cardiovascular disease }\end{array}$ & $\begin{array}{l}\text { RF EMR exposure contributed } \\
\text { to a higher risk of becoming } \\
\text { hypertensive and dyslipidemic }\end{array}$ & {$[121]$} \\
\hline $\begin{array}{l}\text { Intermittent } 16.7 \mathrm{~Hz} \mathrm{MF} \text {, } \\
7.5 \mathrm{hrs} / \text { day and } 240 \text { working } \\
\text { days/year was assumed }\end{array}$ & Railway workers & $\begin{array}{l}\text { Cohort study } \\
\text { Cause of death from death } \\
\text { certificates, } \\
\text { average ELF-MF exposure } \\
\text { determined by measurements } \\
\text { and modelling }\end{array}$ & $\begin{array}{l}\text { No association between } \\
\text { long-term exposure to MF } \\
\text { and death from arrhythmia } \\
\text { related heart diseases or AMI }\end{array}$ & {$[4]$} \\
\hline EMF from incubators & Newborn babies & $\begin{array}{l}\text { 15-minute HRV measurement } \\
\text { in supine position at least } 1 \\
\text { hour after feeding }\end{array}$ & Alterations in HRV & {$[116]$} \\
\hline
\end{tabular}

exposure. A significantly higher frequency of irregularity identified as conduction, rhythm, or repolarization disturbances in resting and 24-hour ECG (electrocardiography) was noticed among subjects exposed to medium frequency when compared to control [120]. Stress is considered to increase B.P. (blood pressure) and exposure to EMFs has been implicated to cause stress $[103,111]$. Vangelova and colleagues [121] found significantly higher systolic and diastolic B.P., total cholesterol, and low-density lipoprotein cholesterol levels in radio operators exposed to RFR and confirmed stronger association between RFR-EMF exposure and the likelihood of becoming hypertensive and dyslipidemic. The researchers, however, noted that the results could be influenced by the extended shifts and monotonous work as well. The study also revealed that majority of the hypertensives who were under medication reached their normal B.P. only when stayed away from the station. Earlier findings have also reported increased hypertension with RFR exposures [115]. Significantly higher levels of stress biomarkers like adrenaline, noradrenaline, and cortisol have been documented in medical staffs with RFR-EMF exposures, which could also influence B.P., heart rate (HR), and so forth, [103]. Recent findings have highlighted the possibility of small short-term and mediumterm effects on HR and cerebral blood flow to intermittent universal mobile telecommunication system (UMTS) exposures [122]. Andrzejak and coworkers [123] reported an increased parasympathetic tone and decreased sympathetic tone during MP use measured by HRV analysis and indicated the potential of MPs in affecting the autonomic balance in healthy individuals. However, the confounding effect of talking during measurement of the parameters cannot be neglected. Similar results of sympathetic domination and parasympathetic suppression were reached by Kodavanji et al. [124] pointing towards the link between long-term MP use and adverse effects on HRV, thereby affecting the autonomic balance in healthy individuals. However, since the study was undertaken on a small population without randomization, the results need further confirmation. To add, a recent investigation with the intent to find the effect of RFR-EMF from MP on the electrocardiographic parameters in ischemic heart disease patients taking into account the gender aspect reached some interesting results. They observed prolongation 
of QT interval in male subjects with or without ischemic heart disease in addition to interference with voltage property of ECG records in myocardial ischemia patients excluding the female counterparts from these effects [125]. In the midst of studies reporting positive findings, parallel studies reporting absence of effects [126-128] create confusion and hampers our understanding. Further long-term studies with better exposure characterization and health assessment are essential to depict the true picture in light of the prevailing controversy with the employment of the latest techniques. In this connection, EMF effect on newborns and patients with electronic implants or on life supporting systems needs immediate attention.

2.6. Effects on Nervous System. The inability of neuronal cells to divide and repair once damaged makes the organism susceptible to develop several neurodegenerative diseases. The occurrence of Parkinson's disease, and so forth, has been linked to cumulative DNA damage in brain tissues [60]. The increased prevalence of Alzheimer's disease reported among workers of textile factories exposed to ELF-MFs [129] could be one such instance. Ahlbom and coworkers [54] in their review also indicated towards a possible relation between amyotrophic lateral sclerosis (ALS) and occupational ELFEMF exposure. However, effect of confounders cannot be ruled out. Cognitive performances like attention, perception, and memory have been reported to diminish instantly by $50 \mathrm{~Hz}, 1 \mathrm{mT}$ ELF-EMF exposure in human subjects [130]. In concert, authors have found significant alterations in learning and information acquisition in passive avoidance learning task in both male and female mice exposed to $8 \mathrm{mT}, 50 \mathrm{~Hz}$ ELF-EMF [131]. Authors have also found association between occupational ELF-EMF exposures and problems like dementia and depression $[132,133]$. Results from animal studies in mice have also established the induction of depression at ELF-EMF exposures due to increased nitric oxide levels in cortex, hippocampus, and hypothalamus [134]. Studies have indicated that short-term ELF-EMF exposure may cause small alterations in neurotransmitter metabolism and in circulating amino acids [90] as well as influencing monoamine metabolism when exposure is in the same direction as the mouse position [42]. In connection, Rajeswari et al. [135] highlighted the importance of orientation of the field exposure with respect to the subject in human experiments. They found the subjects to be restless and aggressive when exposed to pulsations in north orientation, and cholinesterase levels in serum were significantly increased. In east, west, and south orientations, the subjects appeared to be calm and serum cholinesterase levels were normal, which suggested the increase of cholinesterase due to MF stress. Prato and colleagues [136] have reported significant inhibitory effects of a variety of ELF-MFs on endogenous opioid and exogenous opiate induced analgesia in snail Cepacea. Zecca et al. [137] found that higher field strength exposure may raise norepinephrine levels in pineal gland of rats accompanied with key changes in brain involving opioid system in frontal cortex, parietal cortex, and hippocampus. Pertaining to this, the documented calcium ion efflux from brain tissue at RFR exposure can be an important neurochemical effect as their significance in routine nervous system operation is well known, for example, neurotransmitter release for cellular interaction [138].

With reference to RFR-EMF, authors have reported that RFR-EMFs interact with cognitive functions like shortening of reaction times, particularly during tasks that require attention or manipulation of information in the working memory [27, 143]. In yet another study, shorter latency in passive avoidance task was registered in MP RF-EMF exposed rats reflecting significant impairments in memory retention and retrieval [144]. The authors suggested that the RFREMF exposure induced damage might lead to alterations in neuronal functioning of both hippocampus and amygdala resulting in changed behaviour during task performance. A cross-sectional study meant to detect neurobehavioural deficits among residents living close to base stations found the prevalence of neuropsychiatric complaints such as memory changes, headache, sleep disturbance, depressive symptoms, dizziness, and tremors to be significantly higher among exposed inhabitants than controls [145]. The study outcomes were based on a questionnaire survey, clinical examination, neurobehavioural test battery (NBTB), and environmental measures with age, sex, education level, smoking habit, occupation, and MP use matching. The NBTB indicated that the exposed inhabitants exhibited a significantly lower performance than controls in one of the tests of attention and short-term auditory memory. The inhabitants opposite the station showed a major reduction in performance in problem-solving test than those under the station. However, in the tests of visuomotor speed and one test of attention the exposed individuals performed significantly well as compared to controls. A cross-sectional community based study conducted among hand-held cellular telephone users in Singapore found headache to be the most prevalent central nervous system symptom as compared to nonusers and the prevalence increased significantly with increased duration of usage per day [146]. The findings were further substantiated by reduced prevalence by more than $20 \%$ among those who used handsfree equipment as opposed to those who never used them. The reduced exposure as a result of using handsfree equipment could be possible because the antenna is kept farther away from the head. Studies have proved the sensitivity of brain cells towards RFR-EMF exposures [139, 140]. Significant increases in brain glucose metabolism in regions closest to MP antenna have been observed with acute exposures [147]. GSM-MP radiations have been demonstrated to induce seizures in rats made seizure prone by subconvulsive picrotoxin doses and to alter the cerebral activity reflected by significantly higher c-Fos levels in some brain regions, which raises question for persons with epileptic disorders [15]. MP-EMFs have been suggested to affect the normal neurophysiology through alterations in cortical excitability as a result of demodulation or direct interference with membrane ionic changes, which results in depolarisation and excitation of nerve cells [53]. However, no histopathological changes have been observed with long-term MP exposures [148]. Increased BBB permeability has also been documented not only immediately but also after seven days of exposure to MPs [30]. So far, the 
TABLE 5: Studies concerning the health effects of electromagnetic fields on the nervous system.

\begin{tabular}{|c|c|c|c|c|}
\hline EMF characteristics & Study group & Method & Study outcome & Reference \\
\hline $\begin{array}{l}1 \mathrm{mT} 50 \mathrm{~Hz} \text { EMF plus } 45 \mathrm{~dB} \\
\text { SPL (expand) noise for } 1 \mathrm{hr} \\
\text { duration }\end{array}$ & 66 subjects & Double-blind study & $\begin{array}{l}\text { Decreased cognitive } \\
\text { performance in attention, } \\
\text { perception, and memory }\end{array}$ & {$[130]$} \\
\hline $\begin{array}{l}\text { Four different groups with } \\
\text { different durations, days, } \\
\text { orientation, and levels of EMF } \\
\text { exposure }(60 \mathrm{~Hz}, 1,3.3 \text {, } \\
10 \text { Gauss) }\end{array}$ & Male C57BL mice & $\begin{array}{l}\text { Concentrations of DOPAC } \\
\text { HVA }^{\dagger} \text {, and 5-HIAA } \\
\text { tissue were determined with } \\
\text { HPLC-ECD }\end{array}$ & $\begin{array}{l}\text { Monoamine levels are affected } \\
\text { only by EMF when the } \\
\text { exposure is in the same } \\
\text { direction as the mouse } \\
\text { position. }\end{array}$ & {$[42]$} \\
\hline $\begin{array}{l}700 \mathrm{MHz} \text { continuous } \\
\text { RF-EMF, } 25.2-71.0 \mathrm{~V} / \mathrm{m} \text {, } \\
5-15 \mathrm{~min}\end{array}$ & Slices of rat hippocampus & Evoked field potential & $\begin{array}{l}\text { Increases in the level of } \\
\text { neuronal excitability }\end{array}$ & [139] \\
\hline $900 \mathrm{MHz}$ CW MP emissions & $\begin{array}{l}15 \text { subjects, two sessions for } \\
45 \mathrm{~min}\end{array}$ & $\begin{array}{l}\text { Recording of motor evoked } \\
\text { potential using paired-pulse } \\
\text { paradigm, tympanic } \\
\text { temperature }\end{array}$ & $\begin{array}{l}\text { Influence on motor cortex } \\
\text { excitability }\end{array}$ & [140] \\
\hline ELF-MFs & Mice Balb/c & Y-maze & $\begin{array}{l}\text { Impairment in spatial } \\
\text { recognition memory } \\
\text { depending on field strength } \\
\text { and length of exposure }\end{array}$ & {$[141]$} \\
\hline $\begin{array}{l}\mathrm{GSM} 900 \mathrm{MHz} \text { from } \mathrm{MP}, \\
2 \mathrm{~h} / \text { days for } 4 \text { days at } \mathrm{SAR}= \\
0.41 \text { to } 0.98 \mathrm{~W} / \mathrm{kg}\end{array}$ & 16-week-old female rat & Morris water maze & $\begin{array}{l}\text { Reduced ability to consolidate } \\
\text { and retrieve the learned } \\
\text { spatial information }\end{array}$ & {$[27]$} \\
\hline $\begin{array}{l}900 \mathrm{MHz} \text { EMF ( } 1 \mathrm{~h} / \text { day for } 28 \\
\text { days) SAR- } 0.016 \text { whole body } \\
\text { and } 2 \mathrm{~W} / \mathrm{kg} \text { (locally in the } \\
\text { head) }\end{array}$ & $\begin{array}{l}\text { Sham exposed group, } 16 \text { rats, } \\
\text { and four exposure groups, } \\
\text { each with eight rats }\end{array}$ & $\begin{array}{l}\text { Number of pyramidal cells in } \\
\text { CA }^{9} \text { region in hippocampus } \\
\text { following postnatal exposure, } \\
\text { histopathological evaluations } \\
\text { on sections of CA region }\end{array}$ & $\begin{array}{l}\text { Significant reduction in } \\
\text { pyramidal cell number in the } \\
\text { CA of the EMF group }\end{array}$ & {$[142]$} \\
\hline $\begin{array}{l}\text { GSM } 915 \mathrm{MHz} \text { for } 2 \mathrm{~h} \text { in } \\
\mathrm{TEM}^{\S} \text { cells at SARs of } 0,0.12 \text {, } \\
1.2,12 \text { and } 120 \mathrm{~mW} / \mathrm{kg}\end{array}$ & $\begin{array}{l}\text { Forty-eight inbred male and } \\
\text { female Fischer } 344 \text { rats }\end{array}$ & $\begin{array}{l}\text { Histopathological assessment } \\
\text { of albumin extravasation over } \\
\text { the BBB, neuronal albumin } \\
\text { uptake, and neuronal damage }\end{array}$ & $\begin{array}{l}\text { Interruption of BBB } \\
\text { permeability as evidenced by } \\
\text { enhanced albumin } \\
\text { extravasation in exposed rats } \\
\text { after seven-day recovery } \\
\text { period }\end{array}$ & {$[30]$} \\
\hline
\end{tabular}

most reliable findings have been reached regarding the brain electrical activity [10]. Impairment in spatial learning and memory functions has been demonstrated in animal studies $[27,143]$. Details of investigations with exposure characteristics have been tabulated (Table 5). Lai et al. [28] pointed towards $2450 \mathrm{MHz} \mathrm{MW}$ induced short-term memory deficits in rats by the stimulation of endogenous opioids in brain resulting in depressed cholinergic activity responsible for memory functions. The results of $\mathrm{Xu}$ et al. [149] pointed towards the connection between extended low intensity GSM $1800 \mathrm{MHz}(2.4 \mathrm{~W} / \mathrm{kg})$ exposure and synaptic activity evident by decreased excitatory synaptic activity and excitatory synapse number in cultured rat hippocampal neurons. A study investigated the effect of GSM modulated $900 \mathrm{MHz}$ RFEMF at $1 \mathrm{~W} / \mathrm{kg}$ on neuron development in two different cell systems by the assessment of morphological parameters and mRNA expression for $\beta$-thymosin and stress-related proteins [150]. The authors found a diminution in neurite generation from the soma without any effect on branching and neurite length in both the cellular systems, which was also found to be associated with $\beta$-thymosin mRNA overexpression. Yuasa et al. [151] conducted an investigation in order to study the acute effects of pulsed high frequency MP-EMF emissions used for $30 \mathrm{~min}$ on somatosensory evoked potentials (SEPs) in healthy individuals. They demonstrated negative effects on SEPs as well as their recovery function indicating the absence of immediate effects on the sensory cortex. EMRs from MP base stations may expose residents to risk of developing neuropsychiatric difficulties and alterations in performance of neurobehavioural functions either by inhibition or facilitation [145]. The comparative analysis of studies relating cognitive and nervous system performance with EMF experience gets complicated due to different assessment tools employed and exposure situations and despite the bulk of scientific evidence, the results turn into conflicting and unconvincing outcomes. At present, the precise mechanism of EMF ill effects on neurons lacks sound understanding; however, some investigations have indicated the role of lipid 
peroxidation and free radical generation $[2,152]$. To add, the nervous system is chiefly helpless to ROS insults because of its high metabolic rate, inadequate oxidant protection, and reduced cellular turnover [152].

2.7. Effects on Reproductive Functions. Rising male infertility cases in recent times have led to scientific investigations, which indicate the involvement of EMRs as one of the possible environmental factors [153]. Understanding of EMF effect on reproductive functioning is also clouded by contradictory findings [154] despite several decades of research. MPs rather than being a status symbol nowadays have become a part and parcel of everyone's life since the past decade and a half [155]. As it is often carried in pockets in very close proximity to body and the reproductive system, effect of the same on male infertility is an important issue, which seeks immediate attention. Various studies have been undertaken to investigate the potential of ELF field characteristics in inducing damage to the reproductive system [156-160]. In this regard, intermittent $50 \mathrm{~Hz}$ low frequency horizontal EF exposure has been reported to cause significant histopathological alterations like focal tubular atrophy, necrosis, and seminiferous epithelial erosion in rat testis [156]. The serum testosterone levels, however, did not differ significantly between exposed and control groups. Toxic effects of $60 \mathrm{~Hz}, 1 \mathrm{mT}$ ELF-EMF were also reported in male rat offspring exposed from gestation day 13 to postnatal day 21 [159]. The study found a reduction in the count, diameter, area, and volume of seminiferous tubules and height of seminiferous epithelium along with leydig cell count indicative of the harmful effects on testis development. On the contrary, $60 \mathrm{~Hz}, 500 \mu \mathrm{T}$ exposure for 21 hours/day from gestation day 6 to postnatal day 21 in pregnant rats did not elicit any significant difference between the exposed and the controls with regard to spermatogenesis and fertility in male offspring [160]. With reference to investigations in mice, $60 \mathrm{~Hz}$ EMF was found to raise significantly the germ cell death and defects in seminiferous tubules without any effect on the body or testes weights. At the same time, the same frequency of EMF at $0.5 \mathrm{mT}$ was shown to induce DNA breakage though cell survival was not significantly impaired [157]. Another study at $60 \mathrm{~Hz}, 14 \mu \mathrm{T}$, and $200 \mu \mathrm{T}$ reported the induction of apoptosis in mice testicular germ cells [158].

As regards RF-EMF exposure, animal studies undertaken so far document higher levels of sperm head abnormalities, positively correlated to RF-EMF exposures suggesting a doseresponse effect [165]. Aitken et al. [166] reported alterations in genome of epididymal spermatozoa in mice exposed to $900 \mathrm{MHz}$ RF-EMW, $12 \mathrm{~h}$ /day for 7 days. Parallel studies in rats have documented lower spermatocyte counts along with leydig cell hyperplasia and elevated testosterone levels at $2.45 \mathrm{GHz}$ frequency [154]. Significant decline in protein kinase $\mathrm{C}$ and total sperm count together with increased apoptosis was reported in male rats exposed to RF-EMF (2 hours/days, 35 days, $0.9 \mathrm{~W} / \mathrm{kg}$ ) from MPs [167]. The investigators indicated the possible role of ROS behind these findings. Previous study on rats found major impairments in OS equilibrium in reproductive tissues along with modified semen parameters reflecting the fundamental connection between
RF-EMR exposures and mutations in semen quality [168]. In contradiction, no difference in testicular function was found at GSM-RF exposure from cellular phone in rats [169]. An in vitro study assessing the effect of $900 \mathrm{MHz} \mathrm{MP}$ radiation at a SAR of $2.0 \mathrm{~W} / \mathrm{kg}$ on human sperm's fertilizing potential found no harmful effects on acrosome reaction [170]. However, the researchers did reach significant findings with regard to sperm morphometry and a measurable decline in sperm binding to hemizona was found thus indicating a significant effect of RF-EMF on male fertilizing potential. Interesting findings were reached in a study evaluating the effects of RFR released from GSM multiband MP $(900 / 1900 \mathrm{MHz}$ at a SAR of $1.4 \mathrm{~W} / \mathrm{kg}$ ) in Drosophila melanogaster exposed during the 10-day developmental period from egg laying through pupation [171]. The authors reported elevation in offspring count, stress protein hsp70 concentration, and binding activity of serum response element (SRE) in conjunction with phosphorylation of nuclear transcription factor, ELK-1 indicative of cellular stress, which could further lead to critical alterations in the organism. Observational studies conducted in connection to RFR-EMF exposure reported diminution in semen quality by reduced sperm count, motility, viability, and normal morphology which were also found to be a function of duration of MP use [163]. Wdowiak et al. [172] also demonstrated an increase in the proportion of sperm cells with abnormal morphology and a decrease in the proportion of rapid progressive sperms with the frequency of exposure from GSM-MPs. Davoudi et al. [161] also reported a decrease in rapid progressive motile sperm due to GSM-MPs. The details of investigations have been summarised in Table 6. Extended MP uses have been reported to elicit harmful effects on sperm motility in previous researches as well $[162,173]$. Studies show a possible relationship between occupational exposure to radiofrequency equipment including radar and reduced fertility and sperm quality $[164,174]$. Epidemiological investigations have indicated a link between male infertility and MP use, but the mechanism of action is unclear. The role of hyperthermia in causing infertility is apparent but the nonthermal effects are debatable [154]. However, it has been speculated that the effect could be specific to EMR effect, a thermal effect, or due to the combination of both [168]. So far, motility or sperm movement is the only factor observed to be affected significantly [155]. Reproductive functions like meiosis, fertilization, and so forth are particularly vulnerable to toxic insults [154]. De Iuliis et al. [153] have highlighted the occurrence of ROS and DNA fragmentation after RFEMR exposure putting a question mark on the safety of MP use especially in the context of fertility and children's health. Until now, the malfunctioning porous cell membrane and disrupted calcium homeostasis along with OS can be accounted for the damaging effects on testicular cells [12]. Conclusive outcomes have not yet been reached despite extensive researches. So far, long-term studies concerning EMF effects on male reproductive functions are lacking to substantiate the findings and give any clue regarding the biointeraction mechanisms. As far as effect on female reproductive system is concerned, there is limited number of studies. RFR from MPs and base stations have been shown to mutate prolactin but not progesterone levels indicating 
TABLE 6: Studies concerning the health effects of electromagnetic fields on the reproductive system.

\begin{tabular}{|c|c|c|c|c|}
\hline EMF characteristics & Study group & Method & Study outcome & Reference \\
\hline GSM-MP, $6 \mathrm{~h} /$ day for 5 days & MP users & Semen analysis & $\begin{array}{l}\text { Decrease in rapid progressive } \\
\text { motility of sperm }\end{array}$ & {$[161]$} \\
\hline MP & MP users & Semen analysis & $\begin{array}{l}\text { Duration of use and } \\
\text { transmission time correlated } \\
\text { positively and negatively with } \\
\text { proportion of slow progressive } \\
\text { and rapid progressive motile } \\
\text { sperm, respectively. }\end{array}$ & {$[162]$} \\
\hline MP & $\begin{array}{l}\text { MP users with suitable } \\
\text { controls }\end{array}$ & $\begin{array}{l}\text { Sperm parameters like } \\
\text { volume, liquefaction time, } \mathrm{pH} \text {, } \\
\text { viscosity, sperm count, } \\
\text { motility, viability, and } \\
\text { morphology }\end{array}$ & $\begin{array}{l}\text { Statistically significant } \\
\text { decrease in semen quality } \\
\text { which was also a function of } \\
\text { duration of MP use. }\end{array}$ & {$[163]$} \\
\hline MP, $1 \mathrm{~h}$ & Human semen samples & Semen analysis & $\begin{array}{l}\text { Significant decline in semen } \\
\text { mobility, viability and } \\
\text { ROS-TAC }{ }^{*} \text { score, rise in ROS } \\
\text { level. }\end{array}$ & {$[164]$} \\
\hline $\begin{array}{l}1.8 \mathrm{GHz} \text { RF EMR, SAR } \\
(0.4 \mathrm{~W} / \mathrm{kg} \text { to } 27.5 \mathrm{~W} / \mathrm{kg})\end{array}$ & Purified human spermatozoa & $\begin{array}{l}\text { Vitality, motility, sperm } \\
\text { density, } \mathrm{DHE}^{\dagger} \text { assay, MSR } \\
\text { assay, } 8-\mathrm{OH}-\mathrm{dG}^{\dagger}, \text { TUNEL } \\
\text { assay, and flow cytometry }\end{array}$ & $\begin{array}{l}\text { Significant decrease in } \\
\text { motility and vitality and } \\
\text { increase in ROS, 8-OH-dG } \\
\text { and DNA fragmentation with } \\
\text { increasing SAR. }\end{array}$ & {$[153]$} \\
\hline $\begin{array}{l}\text { RF radiations from GSM base } \\
\text { station, } 6 \text {-month exposure }\end{array}$ & Male mice, Mus musculus & Sperm head abnormality assay & $\begin{array}{l}\text { High level of sperm head } \\
\text { injury in exposed mice which } \\
\text { correlated positively with } \\
\text { radiation levels }\end{array}$ & {$[165]$} \\
\hline
\end{tabular}

the consequent effects on menstruation and pregnancy [98]. Miscarriage risks have been shown to be higher in pregnant physiotherapists due to their occupation [175]. Han et al. [176] found significant rise in risk of embryo growth cessation in the first pregnancy trimester of pregnant women especially with the medical history of embryo growth termination with regard to increased exposures from television and MPs. Animal investigations also support the toxic effects of RFR. In this connection, Gul et al. [177] registered a fall in follicles count in rat ovaries submitted to intrauterine RF exposures whereas Xu et al. [178] demonstrated toxic alterations in the reproductive organs. Further studies in females are wanted with special relevance for pregnant women, who are also carrying the future generation. Children form yet another group of prime importance since their reproductive systems are immature and exposures are prolonged; hence, they can be the worst sufferers.

2.8. Auditory and Ocular Effects. A recent study [179] concluded that higher ELF-EMF exposure at $50 \mathrm{~Hz}, 10.182 \mathrm{kV} / \mathrm{m}$ coupled to $4.45 \mathrm{pT}$ MF may give rise to adverse auditory effects especially to the organ of Corti and outer hair cells as a result of decreased distortion product auto acoustic emission amplitudes in higher frequency region localized in basal turn of cochlea in rabbits which have also resemblance with human's frequency spectra. As regards RFR-EMF, MP use has been associated with tinnitus and acoustic neuroma $[38,41]$. Ear is the first biological structure to be hit by
EMFs from MP. In addition, relatively greater vulnerability of cochlear outer hair cells to injuries from a diversity of exogenous and endogenous agents makes the system a victim of radiation emissions $[179,180]$. These days, about $50 \%$ of world's population possesses a MP [30] and even greater than that are experiencing EMF emissions through "passive mobile phoning" [181]. Hearing problems reported in few observational studies [50] have also been investigated to occur in animals [179] with parallel contradictions [180, 182]. Studies with ten minutes acute MP radiation exposures have resulted in no immediate effect on hearing threshold level of pure tone audiometry, transient evoked otoacoustic emissions [183], auditory brain stem response [184], and any depreciation in hearing in young human volunteers. However, regular long-term MP use has been linked to increased relative risk of acoustic schwannoma [39]. Despite the interests in EMF effects due to MP, there is lack of solid evidence regarding the ill effects on auditory system and, hence, we are far from any conclusion and not able to develop safe and sound communication devices necessary for safeguarding one of the senses [11].

Heat-related skin injury and lens defects reported in eyes of man are the only undisputed harmful effects of MW exposure [56]. Carpenter [185] in late seventies reported that microwaves have the capability to induce cataracts and affect the eyes by reducing the ascorbic acid content of the lens coupled with the inhibition of DNA synthesis and mitosis in lens epithelium thereby slowing down the recovery 
process. In addition, the lens becomes more vulnerable to EMF threats because of decreased water content and absence of vasculature $[12,56,186]$. Spector [187] suggested the role of OS in cataract development due to extensive oxidation of lens protein and lipid at older age. Nevertheless, the database is yet deficient to decide regarding ocular defects including cataracts in human subjects exposed for extended durations.

2.9. Effects on Sleep Parameters. Sleep insufficiency was observed to be more common in the occupational group of electronic equipment repairers exposed to ELF-EMF though not statistically significant when compared to controls [89]. Earlier studies have also documented diminished sleep and sleep efficiency with $60 \mathrm{HzMF}$ experience [188]. So far, studies evaluating sleep quality in the context of ELF-EMF exposure in humans have not reached any statistical significance $[44,45,89]$.

In connection to RFR-EMF, Abelin et al. [189] reported the prevalence of difficulties of falling asleep and, in particular, maintaining sleep, which increased with increasing RF-EMF exposure in the vicinity of short-wave broadcast transmitter. In addition, sleep quality was found to improve after interruption of the exposure. A similar study found an association of EMF exposure with sleep quality and melatonin excretion but only in poor sleepers suggesting the sensitivity of a group of people [190]. The authors highlighted that the absence of blinding in their investigation could lead to such results. Another study by Wiholm et al. [191] indicated the negative influence on sleep component during laboratory exposure to $884 \mathrm{MHz}$ wireless signals. Besides, volunteers with no self-reported symptoms related to MP use appear to have more headaches during actual RF exposure as compared to sham exposure. Several studies evaluating RF exposure effects on sleep parameters and sleep EEG are surrounded with contradictory outcomes owing to methodological limitations like small sample sizes and lack of replications of the previous findings. According to a clinical review [192], sleep disturbances do not seem to be a predominant complaint under exposure to high frequency EMF and with the present level of knowledge no final conclusion can be drawn concerning any potential health hazard. Hutter et al. [34] also reported no significant effect on sleep quality and pointed that it could be dominated by the fear of negative health effects of EMF radiations as well as age. Sleep is an important component of the biological species to overcome the daily wear and tear. Studies relating EMF exposures to sleep do suggest some biological effects; however, these do not provide evidence for any adverse health consequences. Further research with well-designed protocols is required with lessons from past experiments so that valuable information is updated in bioelectromagnetics field.

\section{Mechanisms of Action}

3.1. Thermal and Nonthermal Interactions. Due to lack of sufficient energy required to break the molecular bonds in cells by EMFs, the elicited effects are assumed to be indirect and secondary to other induced biochemical modifications $[60$,
76]. Ruediger [32] suggested the indirect role of microthermal processes, OS and altered DNA repair mechanisms behind the observed effects. However, studies have also pointed towards the involvement of resonance-like sensing mechanisms working only at specific combinations of frequency and amplitude suggestive of a direct EMF effect [136]. It is proposed that low frequency time varying electric fields (EFs) interact with the body by the induction of electric currents, formation of electric dipoles, and reorientation of existing dipoles whereas interaction of time-varying MFs leads to induced EFs and circulating electric currents. Higher current densities and EFs have been shown to be induced when the direction of external EF is parallel to the longer vertical axis of body (from head to feet) and the MFs are from front to back, respectively, due to better coupling with human body compared to other configurations [193]. Additionally, EMF effects are dependent on a number of physical (frequency, modulation, polarization, wave characteristics, near or far field configuration, duration and orientation of EF and MF exposure, dielectric properties, conductivity and water content of tissues, and environmental factors like humidity, temperature, etc.) and biological variables (species, shape and size of the body, weight, geometry of the body, and nutritional and health status).

The possible effect of EMF irradiation is either thermal or nonthermal depending on frequency and strength. The elicited effects are assumed to be noticeable when not shrouded by thermal noise also termed as Brownian motion which is a virtue of all objects/materials above absolute zero temperature. The thermal effects are induced as a consequence of heat gained by water contained in body tissues. Hence, body tissues or organs like lens of eye and testes with less vasculature or deficient in water content are the most vulnerable to even small rise in temperature. Usually, body parts with the smallest cross-section like hand, feet, fingers, and toes gain the maximum values of current densities and EFs [193].

3.2. Oxidative Stress. OS resulting from imbalance of reactive oxygen species (ROS) and antioxidants, leading to disruption of cell functions, has been proposed as one of the probable modes of EMF action [2, 5, 60, 71, 196]. EMFs have also been implicated to lengthen life of free radicals particularly by Fenton reaction [33], affect enzyme activity [31], and change protein levels indicative of induction of cellular stress response pathways [14]. Fenton reaction is a process in which hydroxy free radicals are generated from hydrogen peroxide produced during mitochondrial oxidative respiration in presence of transition metals like iron [60, 64]. EMF interaction with free radicals and transitional metals has also been linked to the observed genotoxic effects $[33,64]$. In this regard, cells, which are metabolically active, or have higher cellular concentrations of free iron and superparamagnetic iron particles (magnetites) in body tissues like brain cells, are more vulnerable to EMFs [60]. Several studies have demonstrated OS inducing ability of EMF including MP-RFR in different animal models [31, 152, 196-198] or in cell cultures $[64,73]$ paralleled with negative findings as well $[5,7]$. Studies 
TABLE 7: Studies showing the oxidative stress inducing ability of electromagnetic fields.

\begin{tabular}{|c|c|c|c|c|}
\hline EMF characteristics & Study group & Method & Study outcome & Reference \\
\hline $\begin{array}{l}2450 \mathrm{MHz} \text { pulsed }(2 \mathrm{msec} \\
\text { pulses, } 500 \mathrm{pps}), 2 \mathrm{~mW} / \mathrm{cm}^{2} \text {, } \\
\text { Avg. } \mathrm{SAR}=1.2 \mathrm{~W} / \mathrm{kg}, 2 \mathrm{~h}, \\
\text { melatonin and } \mathrm{PBN}{ }^{*} \\
\text { treatment before and after } \\
\text { exposure }\end{array}$ & Male Sprague Dawley rats & $\begin{array}{l}\text { Microgel electrophoresis assay } \\
\text { in brain cells }\end{array}$ & $\begin{array}{l}\text { Involvement of free radicals in } \\
\text { inducing DNA damage in } \\
\text { brain cells, and protective } \\
\text { effects of melatonin andPBN } \\
\text { as free radical scavenger }\end{array}$ & [3] \\
\hline $\begin{array}{l}0.1 \mathrm{mT}, 60 \mathrm{~Hz}, 5 \mathrm{~h} \text { and } 30 \mathrm{~min} \\
\text { after } \mathrm{LPS}^{\dagger} \text { administration, } \\
\text { mice were administered with } \\
\mathrm{NO}^{\ddagger} \text { spin trap MGD-Fe }\end{array}$ & $\begin{array}{l}\text { Male } \\
\text { BALB/C mice }\end{array}$ & $\mathrm{EPR}^{\S}$ measurement in liver & $\begin{array}{l}\text { EMF increased LPS induced } \\
\text { NO production but not alone }\end{array}$ & [194] \\
\hline $\begin{array}{l}900 \mathrm{MHz}, 30 \mathrm{~min} / \text { day, } 5 \\
\text { days/wk for } 2 \text { weeks, mel. } \\
(10 \mathrm{mg} / \mathrm{kg} \text { daily orally) }\end{array}$ & $\begin{array}{l}\text { Male Sprague Dawley rats in } \\
\text { three groups }\end{array}$ & $\begin{array}{l}\text { NO measurement in nasal and } \\
\text { paranasal mucosa by Griess } \\
\text { reaction }\end{array}$ & $\begin{array}{l}\text { Increase in NO level in sinus } \\
\text { and nasal mucosa, beneficial } \\
\text { effect of melatonin in } \\
\text { preventing these changes }\end{array}$ & [195] \\
\hline $\begin{array}{l}900 \mathrm{MHz} \text { MW, melatonin } \\
(100 \mu \mathrm{g} / \mathrm{kg} \text { sc before daily } \\
\text { exposure) }\end{array}$ & $\begin{array}{l}\text { Sprague Dawley rats in three } \\
\text { groups }\end{array}$ & $\begin{array}{l}\text { Lipid peroxidation in cortex } \\
\text { brain and hippocampus tissue }\end{array}$ & $\begin{array}{l}\text { Rise in MDA" levels, } \\
\text { melatonin caused decline in } \\
\text { hippocampal MDA levels with } \\
\text { no decrease in cortex }\end{array}$ & {$[2]$} \\
\hline $\begin{array}{l}900 \mathrm{MHz} \text { RF, CW \& GSM MP } \\
\text { waves for } 10 \text { or } 30 \mathrm{~min} \text {, } \\
\text { SAR }=0.3 \& 1 \mathrm{~W} / \mathrm{kg}, \mathrm{MX}^{\#}= \\
500 \mu \mathrm{M}\end{array}$ & $\begin{array}{l}\text { Murine L929 fibrosarcoma } \\
\text { cells }\end{array}$ & Measurement of ROS & $\begin{array}{l}\text { No ROS generation either } \\
\text { alone or in association with } \\
\text { MX }\end{array}$ & {$[5]$} \\
\hline $\begin{array}{l}\text { MP, } 20,40,60 \text { days, SAR }= \\
0.043-0.135 \mathrm{~W} / \mathrm{kg}), \text { melatonin } \\
=2 \mathrm{mg} / \mathrm{kg} \text { body weight i.p. }\end{array}$ & Wistar rats in four groups & $\begin{array}{l}\text { Biochemical estimation of } \\
\text { MDA, carbonyl groups, } \mathrm{XO}^{1} \\
\text { and CAT }{ }^{2} \text { activity in brain } \\
\text { tissue }\end{array}$ & $\begin{array}{l}\text { Significant rise in MDA, } \\
\text { carbonyl groups, XO activity, } \\
\text { and reduced CAT activity after } \\
40 \text { and } 60 \text { days exposure; } \\
\text { melatonin ameliorates OS }\end{array}$ & {$[152]$} \\
\hline
\end{tabular}

" PBN: N-tert-butyl-a-phenylnitrone, ${ }^{\dagger}$ LPS: lipopolysaccharide, ${ }^{\ddagger}$ NO: nitric oxide, ${ }^{9}$ MGD-Fe: ferrous N-methyl-D-glucamine dithiocarbamate, ${ }^{\S}$ EPR: electron paramagnetic resonance, ${ }^{\|} \mathrm{MDA}$ : malondialdehyde, ${ }^{\#} \mathrm{MX}: 3$-chloro-4-(dichloromethyl)-5-hydroxy-2(5H)-furanone, ${ }^{1} \mathrm{XO}$ : xanthine oxidase, and ${ }^{2} \mathrm{CAT}$ : catalase.

demonstrating EMF's ability to cause OS are summarised in Table 7. Given the credence of free radicals in signal transduction and EMF in boosting the free radical lifetime, there are chances of EMF influencing signalling [194].

\subsection{Melatonin Diminution. Several human and animal stud-} ies conducted thus far have suggested decrease in melatonin after EMF exposure [21, 23, 24, 87]. Like all other EMF effects, melatonin diminution is also surrounded with conflicting results [87]; however, the effects have been suggested to be somewhat constant, at least in rodents [199]. Some studies have also supported the protective effect of melatonin against oxidative damage induced by EMFs [2, 3, 64, 152, 195] pointing towards the OS mechanism involved in generating negative health outcomes and melatonin's beneficial properties. The hypothesised mechanism of EMF action on melatonin concentration is through the imitation of light rays to the retina [22]. To add, Yaga et al. [86] found significant suppression of $\mathrm{N}$-acetyltransferase (NAT) activity, a ratelimiting enzyme in melatonin synthesis due to MF exposure. The melatonin forming enzyme hydroxyindole O-methyl transferase has also been documented to be affected [87]. Melatonin's shielding actions counter to EMF ill effects are supposed to shoot from its direct free radical foraging and indirect antioxidant property of inhibiting free radical production at the power house of the cell and, hence, diminution of pineal melatonin secretion could be proposed as a possible mechanism of EMF interaction with living organisms.

3.4. Calcium Flux. Calcium ion efflux/influx has also been proposed as the biological mechanism [200] and is dependent on ambient temperature, geomagnetic field intensity, direction, and signal strength [201-203]. Calcium ions are crucial for cAMP pathway as well as serotonin/melatonin conversion and their efflux from pinealocytes is supposed to cause melatonin suppression. Besides, calcium dependent signal transduction systems also have been implicated in the mediation of immune cell effects by low frequency EMF [29]. However, authors have indicated the occurrence of calcium efflux/influx at some specific exposure combinations but not at other relatively closer exposure characteristics mainly due to the "window" effect or nonlinear nature of modulation frequency and intensity effect.

3.5. Molecular Mechanisms. Similar to physiological stress response at the organ system level, there are also cellular stress responses at the cell level to impart protection to the cell from external and internal stressors. The cellular stress response is characterized by an elevation in stress protein concentration [204] in response to a stress causing damage to biomolecules like DNA and proteins [205]. EMFs at ELF, RF, and amplitude 
modulated RF have been demonstrated to stimulate the same stress response $[204,206,207]$. Unlike the past assumption of absence of DNA-EMF interaction plausibility, recent investigations indicate the potential of EMF both ELF and RF to stimulate DNA and induce protein expression [14, 171, 208, 209]. Various studies have highlighted the genotoxic ability of EMF at both ELF and RF range as evidenced from DNA strand break reports post-EMF experience [33, 63-65, 68]. Recent investigations have further revealed the presence of an EMF reactive sequence in DNA [210] which acts particularly in response to EMF stimulus. These EMF reactive DNA sequences code for the production of the chief stress protein hsp70, in response to the binding of transcription factor, heat shock factor 1 (HSE-1) to heat shock element (HSE) in the promoter region [210-213]. Friedman et al. [209] delineated the molecular mechanism behind the stimulation of the ERKs in response to RFR exposure at MP frequencies. The RF-EMF through its interaction with $\mathrm{NADH}$ oxidase in the plasma membrane causes the formation of ROS, which further activate the MMPs (matrix metalloproteinases). Because of activation, the MMPs break into Hb-EGF [heparin-binding EGF (epidermal growth factor)] and stimulate the EGF receptor, which sequentially triggers the ERK cascade. The ERK cascade is one of the four mitogen-activated protein kinase (MAPK) signaling cascades that controls transcription and associated cellular processes like replication, cell-cycle progression, apoptosis, differentiation, metabolism, and so forth, in reaction to extracellular stimuli. The MP radiation induced overexpressed protein transcription factors have been found to regulate the cellular processes such as apoptosis [214] and replication and cell cycle progression [14, 215]. The reported findings with regard to cellular stress response post-EMF experience give critical insights into connection to harmful health-relevant potential of ELFs and RFRs in addition to their role as cellular biomarkers.

In light of several credible biointeraction processes, the OS mechanism appears to gain the maximum support. The hypothesised EMF biointeraction path may involve ROS generation, leading to diminished antioxidant capacity, affecting the antioxidant/prooxidant equilibrium and causing OS, thereby instigating adverse health effects. This sequence may be paralleled by calcium efflux, which alters serotonin conversion into melatonin thus triggering melatonin diminution, which further substantiates OS. At the same time, ROS may lead to the activation of signal transduction pathway trigging the ERK cascade. The cellular stress response mediated by hsp70 overexpression can also be considered but this effect is limited to certain group of cells while other cell types are being nonresponsive [216]. The exact mode of biointeraction mechanism still needs to be elucidated.

\section{Research Needs}

The limited quality of research works in bioelectromagnetics and methodological problems is an important concern [57, 155]. Until now, epidemiological investigations have failed to get the SAR value which is the most direct dosimetric measure of an individual's exposure at the tissue or organ level under study [217]. Moreover, lack of an appropriate exposure assessment method [55] and reliable equipment for calculation of energy absorbed in the body and the intricate relation with species, frequency, power, EMF source, and modulation dosimetry has inhibited the utilization of laboratory results to human conditions [53] and the conduct of epidemiological studies [56]. Hutter et al. [34] suggested the usage of personal "exposimeter" or long-term exposure monitoring as the best way for exposure assessment. So far, errors in exposure assessment due to lack of long-term exposure monitoring by EMF dosimeters, exposure has been assessed by crude methods in most studies, such as wiring codes, occupation or residence in relation to proximity to a source, spot measurements, time-weighted average and selfreports, and hence results in underestimation of actual risk and clouds the true relationship. Absence of suitable control population for comparison as all of us are exposed to EMFs every day coming from varied sources with different degrees further complicates the understanding of literature on human EMF exposure [52, 55].

Furthermore, clear understanding is hampered by the multipart interactions of different EMF exposure factors $[12,53]$ and shape, size, mass, orientation, and electrical characteristics of body and individual characteristics like age, gender, activity level, incapacitation, or illness [218]. Environmental parameters like ambient temperature, wind velocity, humidity, and body insulation also affect the communication between body and the EMF vector. Anatomical differences among humans and animal models as regards size, shape, reproductive tract variations, and so forth further complicate the understanding of observed results [12].

As far as studies investigating exposure of humans to MP radiations are concerned, they have followed the standard method of EMF exposure assessment by retrospective interviews or obtaining information or self-reports of subjects on total duration of use or number of calls, number of years of use, side of use ipsilateral, or contralateral along with exposure duration estimates and billing records from service providers $[52,79]$. However, these parameters have been questioned for recall bias [52]. Animal experimentation especially using primates or species closely related to humans would eliminate the chances of recall bias regarding MP use and give meaningful directions. Besides, the duration based exposure assessment is built on the postulation of equivalent power emissions per minute from all phones which may not be correct with expanding use of GSM based phones with variable power outputs ending in miscalculation of true exposure in spite of recall accuracy [217]. Besides, geographic area, physical environment, user location rural or urban, distance between user and base station antenna, handsfree use, individual characteristics of phone handset, and its use as well as technical features of provider network all have some effect on EMF emissions and consequent exposure to the individuals $[12,34,52,219]$.

A research carried out by Erdreich et al. [217] to increase the accuracy of exposure estimation in epidemiological studies of GSM-MPs found that the average power output rate in GSM phones varies with several characteristics of phone use, the largest being the site of investigation, followed by user movement and location (indoor or outdoor), use of handsfree 
device, and urbanicity. The understanding is complicated further by factors like distance to the phone, holding position, position of antenna, pinna size, elasticity of ear, thickness of skull bone, type of tissue, tissue type distribution, and so forth, governing the actual amount of power absorbed [220]. In addition, lack of long-term studies also restricts our understanding. Apart from this, role of media finds significance in focusing the attention on the potential adverse health effects caused by MP radiations. This may give rise to fear or awareness forcing MP users to report more symptoms than nonusers even if the prevalence of symptoms were equal [146].

Animal and cell culture studies are surrounded with conflicting results as a consequence of the heterogeneous exposure conditions (type of EMF- RF, MW, CW, Pulsed, and so forth, SAR value, exposure duration) $[5,7]$ and differing assay protocols [53]. At the same time, vested interests of sponsors also influence the study outcome with quality studies having mixed funding and, hence, sponsorship should be taken into consideration while interpreting the findings [221]. We strongly advocate that with mere swelling number of studies no fruitful conclusions can be reached. If we do not address the limitations of past investigations, we may not be able to truly contribute to the domain of bioelectromagnetics. Therefore, need of the hour is to do innovative research with sound designs and appropriate methodologies rising above the demerits of past researches.

\section{Conclusion}

Given the ubiquitous nature of EMFs, their widespread applications, and their capability to produce deleterious effects, conclusive investigations of the health risks are critical. With the published literature on EMF, it is still not sufficient enough to reach a concrete conclusion. But the possibility of negative consequences cannot be excluded. Several studies with appropriate methodologies reflect the capacity of EMFs to cause adverse health effects. However, the absence of any established biointeraction mechanism does not diminish the reliability of these studies as there are several credible mechanisms like OS that can account for the observed effects.

Therefore, need of the hour is to restrict the swelling numbers of scientific investigations and in place activate comprehensive well-coordinated blind scientific investigations especially long-term studies overcoming all limitations and demerits of previous findings with suitable replication studies and follow-up. There is a need for standardized research methodology along with the inclusion of appropriate exposure assessment technique which is crucial for identification of dose response relation if any and the elucidation of mechanism for biological interaction. If we do not work upon the demerits of previous findings, we may remain far from any concrete conclusion. At the same time, it is critical to analyse the EMF investigations giving more weight to the similarities and dissimilarities rather than giving more importance to the endpoints reached.

For the time being, since it is difficult to protect oneself from EMFs, the only practical way to check exposures is to distance oneself from the source. Together, the precautionary approach and ALARA (as low as reasonably achievable) principle can also be applied to save us from substantial exposures and the possible ill effects if any. The objective is to minimize EMF exposures to the greatest degree possible without significant economic cost and disturbance.

\section{Conflict of Interests}

The authors declare that there is no conflict of interests regarding the publication of this paper.

\section{Acknowledgments}

The authors are very thankful to Dr. M. P. K. Reddy and Dr. S. N. Singh, DIPAS, DRDO, for their valuable inputs in the preparation of the paper.

\section{References}

[1] V. Garaj-Vrhovac, G. Gajski, S. Pažanin et al., "Assessment of cytogenetic damage and oxidative stress in personnel occupationally exposed to the pulsed microwave radiation of marine radar equipment," International Journal of Hygiene and Environmental Health, vol. 214, no. 1, pp. 59-65, 2011.

[2] H. Koylu, H. Mollaoglu, F. Ozguner, M. Naziroglu, and N. Delibas, "Melatonin modulates $900 \mathrm{MHz}$ microwave-induced lipid peroxidation changes in rat brain," Toxicology and Industrial Health, vol. 22, pp. 211-216, 2006.

[3] H. Lai and N. P. Singh, "Melatonin and a spin-trap compound block radio-frequency electromagnetic radiation-induced DNA strand breaks in rat brain cells," Bioelectromagnetics, vol. 18, no. 6, pp. 446-454, 1997.

[4] M. Röösli, M. Egger, D. Pfluger, and C. Minder, "Cardiovascular mortality and exposure to extremely low frequency magnetic fields: a cohort study of Swiss railway workers," Environmental Health, vol. 7, article 35, 2008.

[5] O. Zeni, R. di Pietro, G. d'Ambrosio et al., "Formation of reactive oxygen species in L929 cells after exposure to $900 \mathrm{MHz} \mathrm{RF}$ radiation with and without co-exposure to 3chloro-4-(dichloromethyl)-5- hydroxy-2 $(5 \mathrm{H})$-furanone," Radiation Research, vol. 167, no. 3, pp. 306-311, 2007.

[6] J. Schüz, R. Jacobsen, J. H. Olsen, J. D. Boice Jr., J. K. McLaughlin, and C. Johansen, "Cellular telephone use and cancer risk: update of a nationwide Danish cohort," Journal of the National Cancer Institute, vol. 98, no. 23, pp. 1707-1713, 2006.

[7] G. J. Hook, D. R. Spitz, J. E. Sim et al., "Evaluation of parameters of oxidative stress after in vitro exposure to FMCW- and CDMA-modulated radiofrequency radiation fields," Radiation Research, vol. 162, no. 5, pp. 497-504, 2004.

[8] I. Lagroye, G. J. Hook, B. A. Wettring et al., "Measurements of alkali-labile DNA damage and protein-DNA cross links after $2450 \mathrm{MHz}$ microwave and low-dose gamma irradiation in vitro," Radiation Research, vol. 161, no. 2, pp. 201-214, 2004.

[9] S. J. Genuis and C. T. Lipp, "Electromagnetic hypersensitivity: Fact or fiction?" Science of the Total Environment, vol. 414, pp. 103-112, 2012.

[10] S. J. Regel and P. Achermann, "Cognitive performance measures in bioelectromagnetic research critical evaluation and recommendations," Environmental Health, vol. 10, article 10, 2011. 
[11] A. E. Kaprana, A. D. Karatzanis, E. P. Prokopakis et al., "Studying the effects of mobile phone use on the auditory system and the central nervous system: a review of the literature and future directions," European Archives of Oto-Rhino-Laryngology, vol. 265, no. 9, pp. 1011-1019, 2008.

[12] A. J. Hamada, A. Singh, and A. Agarwal, "Cell phones and their impact on male fertility: fact or fiction," The Open Reproductive Science Journal, vol. 5, pp. 125-137, 2011.

[13] S. B. Mortazavi, A. Safari, A. Khavanin, A. Kazemnejad, S. M. Moazzeni, and R. Abbas, "Induction of micronuclei in mice lymphocytes exposed to microwave and toluene," American Journal of Applied Science, vol. 2, pp. 1321-1324, 2005.

[14] D. Leszczynski, S. Joenväärä, J. Reivinen, and R. Kuokka, “Nonthermal activation of the hsp27/p38MAPK stress pathway by mobile phone radiation in human endothelial cells: molecular mechanism for cancer- and blood-brain barrier-related effects," Differentiation, vol. 70, no. 2-3, pp. 120-129, 2002.

[15] E. López-Martín, J. L. Relova-Quinteiro, R. Gallego-Gómez, M. Peleteiro-Fernández, F. J. Jorge-Barreiro, and F. J. AresPena, "GSM radiation triggers seizures and increases cerebral c-Fos positivity in rats pretreated with subconvulsive doses of picrotoxin," Neuroscience Letters, vol. 398, no. 1-2, pp. 139-144, 2006.

[16] M. Kundi, "Mobile phone use and cancer," Occupational and Environmental Medicine, vol. 61, no. 6, pp. 560-570, 2004.

[17] I. Yakymenko and E. Sidorik, "Risks of carcinogenesis from electromagnetic radiation of mobile telephony devices," Experimental Oncology, vol. 32, no. 2, pp. 54-60, 2010.

[18] "Guidelines for limiting exposure to time-varying electric, magnetic, and electromagnetic fields (up to $300 \mathrm{GHz}$ ). International Commission on Non-Ionizing Radiation Protection," Health Physics, vol. 74, pp. 494-522, 1998.

[19] O. Johansson, "Disturbance of the immune system by electromagnetic fields-a potentially underlying cause for cellular damage and tissue repair reduction which could lead to disease and impairment," Pathophysiology, vol. 16, no. 2-3, pp. 157-177, 2009.

[20] T. Kumlin, P. Heikkinen, J. T. Laitinen, and J. Juutilainen, "Exposure to a $50 \mathrm{~Hz}$ magnetic field induces a circadian rhythm in 6-hydroxymelatonin sulfate excretion in mice," Journal of Radiation Research, vol. 46, no. 3, pp. 313-318, 2005.

[21] J. B. Burch, J. S. Reif, M. G. Yost, T. J. Keefe, and C. A. Pitrat, "Reduced excretion of a melatonin metabolite in workers exposed to $60 \mathrm{~Hz}$ magnetic fields," American Journal of Epidemiology, vol. 150, no. 1, pp. 27-36, 1999.

[22] A. W. Wood, S. M. Armstrong, M. L. Sait, L. Devine, and M. J. Martin, "Changes in human plasma melatonin profiles in response to $50 \mathrm{~Hz}$ magnetic field exposure," Journal of Pineal Research, vol. 25, no. 2, pp. 116-127, 1998.

[23] R. G. Stevens and S. Davis, "The melatonin hypothesis: electric power and breast cancer," Environmental Health Perspectives, vol. 104, no. 1, pp. 135-140, 1996.

[24] D. H. Pfluger and C. E. Minder, "Effects of exposure to 16.7 $\mathrm{Hz}$ magnetic fields on urinary 6-hydroxymelatonin sulfate excretion of Swiss railway workers," Journal of Pineal Research, vol. 21, no. 2, pp. 91-100, 1996.

[25] W. R. Rogers, R. J. Reiter, H. D. Smith, and L. Barlow-Walden, "Rapid-onset/offset, variably scheduled $60 \mathrm{~Hz}$ electric and magnetic field exposure reduces nocturnal serum melatonin concentration in nonhuman primates," Bioelectromagnetics, supplement 3, pp. 119-122, 1995.
[26] T. Jorge-Mora, M. Alvarez-Folgueiras, J. Leiro, F. J. JorgeBarreiro, F. J. Ares-Pena, and E. López-Martín, "Exposure to $2.45 \mathrm{GHz}$ microwave radiation provokes cerebral changes in induction of HSP-90 $\alpha / \beta$ heat shock protein in rat," Progress in Electromagnetics Research, vol. 100, pp. 351-379, 2010.

[27] A. F. Fragopoulou, P. Miltiadous, A. Stamatakis, F. Stylianopoulou, S. L. Koussoulakos, and L. H. Margaritis, "Whole body exposure with GSM $900 \mathrm{MHz}$ affects spatial memory in mice," Pathophysiology, vol. 17, no. 3, pp. 179-187, 2010.

[28] H. Lai, A. Horita, and A. W. Guy, "Microwave irradiation affects radial-arm maze performance in the rat," Bioelectromagnetics, vol. 15, no. 2, pp. 95-104, 1994.

[29] J. Walleczek, "Electromagnetic field effects on cells of the immune system: the role of calcium signaling," The FASEB Journal, vol. 6, no. 13, pp. 3177-3185, 1992.

[30] H. Nittby, A. Brun, J. Eberhardt, L. Malmgren, B. R. R. Persson, and L. G. Salford, "Increased blood-brain barrier permeability in mammalian brain 7 days after exposure to the radiation from a GSM-900 mobile phone," Pathophysiology, vol. 16, no. 2-3, pp. 103-112, 2009.

[31] K. K. Kesari, J. Behari, and S. Kumar, "Mutagenic response of $2.45 \mathrm{GHz}$ radiation exposure on rat brain," International Journal of Radiation Biology, vol. 86, no. 4, pp. 334-343, 2010.

[32] H. W. Ruediger, "Genotoxic effects of radiofrequency electromagnetic fields," Pathophysiology, vol. 16, no. 2-3, pp. 89-102, 2009.

[33] H. Lai and N. P. Singh, "Magnetic field-induced DNA strand breaks in brain cells of the rat," Environmental Health Perspectives, vol. 112, no. 6, pp. 687-694, 2004.

[34] H. P. Hutter, H. Moshammer, P. Wallner, and M. Kundi, "Subjective symptoms, sleeping problems, and cognitive performance in subjects living near mobile phone base stations," Occupational and Environmental Medicine, vol. 63, no. 5, pp. 307-313, 2006.

[35] H. Seitz, D. Stinner, T. Eikmann, C. Herr, and M. Röösli, "Electromagnetic hypersensitivity (EHS) and subjective health complaints associated with electromagnetic fields of mobile phone communication-a literature review published between 2000 and 2004," Science of the Total Environment, vol. 349, no. 1-3, pp. 45-55, 2005.

[36] M. Röösli, M. Moser, Y. Baldinini, M. Meier, and C. BraunFahrländer, "Symptoms of ill health ascribed to electromagnetic field exposure-a questionnaire survey," International Journal of Hygiene and Environmental Health, vol. 207, no. 2, pp. 141-150, 2004.

[37] E. A. Navarro, J. Segura, M. Portolés, and C. Gómez-Perretta, "The microwave syndrome: a preliminary study in Spain," Electromagnetic Biology and Medicine, vol. 22, no. 2-3, pp. 161169, 2003.

[38] L. Hardell, K. Hansson Mild, M. Sandström, M. Carlberg, A. Hallquist, and A. Påhlson, "Vestibular schwannoma, tinnitus and cellular telephones," Neuroepidemiology, vol. 22, no. 2, pp. 124-129, 2003.

[39] L. Hardell, M. Carlberg, and K. Hansson Mild, "Use of cellular telephones and brain tumour risk in urban and rural areas," Occupational and Environmental Medicine, vol. 62, no. 6, pp. 390-394, 2005.

[40] L. Hardell, M. Carlberg, F. Söderqvist, K. H. Mild, and L. L. Morgan, "Long-term use of cellular phones and brain tumours: increased risk associated with use for $>10$ years," Occupational and Environmental Medicine, vol. 64, no. 9, pp. 626-632, 2007. 
[41] L. Hardell and M. Carlberg, "Mobile phones, cordless phones and the risk for brain tumours," International Journal of Oncology, vol. 35, no. 1, pp. 5-17, 2009.

[42] H. Kabuto, I. Yokoi, A. Mori, and N. Ogawa, "Effects of an in vivo $60 \mathrm{~Hz}$ magnetic field on monoamine levels in mouse brain," Pathophysiology, vol. 7, no. 2, pp. 115-119, 2000.

[43] WHO (World Health Organisation), "Electromagnetic hypersensitivity," in Proceedings of the International Workshop on EMF Hypersensitivity, Prague, Czech Republic, 2004.

[44] T. Barsam, M. R. Monazzam, A. A. Haghdoost, M. R. Ghotbi, and S. F. Dehghan, "Effect of extremely low frequency electromagnetic field exposure on sleep quality in high voltage substations," Iranian Journal of Environmental Health Science and Engineering, vol. 9, no. 15, 2012.

[45] M. R. Monazzam, M. Hosseini, L. F. Matin, H. A. Aghaei, H. Khosroabadi, and A. Hesami, "Sleep quality and general health status of employees exposed to extremely low frequency magnetic fields in a petrochemical complex," Journal of Environmental Health Science \& Engineering, vol. 12, article 78, 2014.

[46] E. van Wijngaarden, D. A. Savitz, R. C. Kleckner, J. Cai, and D. Loomis, "Exposure to electromagnetic fields and suicide among electric utility workers: a nested case-control study," Occupational and Environmental Medicine, vol. 57, no. 4, pp. 258-263, 2000.

[47] I. L. Beale, N. E. Pearce, D. M. Conroy, M. A. Henning, and K. A. Murrell, "Psychological effects of chronic exposure to $50 \mathrm{~Hz}$ magnetic fields in humans living near extra-high-voltage transmission lines," Bioelectromagnetics, vol. 18, no. 8, pp. 584594, 1997.

[48] M. Havas, "Electromagnetic hypersensitivity: biological effects of dirty electricity with emphasis on diabetes and multiple sclerosis," Electromagnetic Biology and Medicine, vol. 25, no. 4, pp. 259-268, 2006.

[49] M. Havas and A. Olstad, "Power quality affects teacher wellbeing and student behavior in three Minnesota Schools," Science of the Total Environment, vol. 402, no. 2-3, pp. 157-162, 2008.

[50] M. M. Khan, "Adverse effects of excessive mobile phone use," International Journal of Occupational Medicine and Environmental Health, vol. 21, no. 4, pp. 289-293, 2008.

[51] T. Al-Khlaiwi and S. A. Meo, "Association of mobile phone radiation with fatigue, headache, dizziness, tension and sleep disturbance in Saudi population," Saudi Medical Journal, vol. 25, no. 6, pp. 732-736, 2004.

[52] D. R. Kohli, A. Sachdev, and H. S. Vats, "Cell phones and tumor: still in no man/s land," Indian Journal of Cancer, vol. 46, no. 1, pp. 5-12, 2009.

[53] E. Valentini, G. Curcio, F. Moroni, M. Ferrara, L. de Gennaro, and M. Bertini, "Neurophysiological effects of mobile phone electromagnetic fields on humans: a comprehensive review," Bioelectromagnetics, vol. 28, no. 6, pp. 415-432, 2007.

[54] A. Ahlbom, E. Cardis, A. Green, M. Linet, D. Savitz, and A. Swerdlow, "Review of the epidemiologic literature on EMF and health," Environmental Health Perspectives, vol. 109, no. 6, pp. 911-933, 2001.

[55] D. O. Carpenter, "Possible effects of electromagnetic fields on the nervous system and development," MRDD Research Reviews, vol. 3, pp. 270-274, 1997.

[56] C. Silverman, "Nervous and behavioral effects of microwave radiation in humans," The American Journal of Epidemiology, vol. 97, no. 4, pp. 219-224, 1973.
[57] P. Levallois, "Hypersensitivity of human subjects to environmental electric and magnetic field exposure: a review of the literature.," Environmental Health Perspectives, vol. 110, pp. 613618, 2002.

[58] M. R. Scarfí, A. Sannino, A. Perrotta, M. Sarti, P. Mesirca, and F. Bersani, "Evaluation of genotoxic effects in human fibroblasts after intermittent exposure to $50 \mathrm{~Hz}$ electromagnetic fields: a confirmatory study," Radiation Research, vol. 164, no. 3, pp. 270276, 2005.

[59] Y. H. Cho and H. W. Chung, "The effect of extremely low frequency electromagnetic fields (ELF-EMF) on the frequency of micronuclei and sister chromatid exchange in human lymphocytes induced by benzo(a)pyrene," Toxicology Letters, vol. 143, no. 1, pp. 37-44, 2003.

[60] J. L. Phillips, N. P. Singh, and H. Lai, "Electromagnetic fields and DNA damage," Pathophysiology, vol. 16, no. 2-3, pp. 79-88, 2009.

[61] S. Ivancsits, A. Pilger, E. Diem, O. Jahn, and H. W. Rüdiger, "Cell type-specific genotoxic effects of intermittent extremely lowfrequency electromagnetic fields," Mutation Research-Genetic Toxicology and Environmental Mutagenesis, vol. 583, no. 2, pp. 184-188, 2005.

[62] J. Delimaris, S. Tsilimigaki, N. Messini-Nicolaki, E. Ziros, and S. M. Piperakis, "Effects of pulsed electric fields on DNA of human lymphocytes," Cell Biology and Toxicology, vol. 22, no. 6, pp. 409-415, 2006.

[63] H. Lai and N. P. Singh, "Melatonin and N-tert-butyl- $\alpha$ phenylnitrone block $60-\mathrm{Hz}$ magnetic field-induced DNA single and double strand breaks in rat brain cells," Journal of Pineal Research, vol. 22, no. 3, pp. 152-162, 1997.

[64] J. Jajte, M. Zmyślony, J. Palus, E. Dziubałtowska, and E. Raikowska, "Protective effect of melatonin against in vitro iron ions and $7 \mathrm{mT} 50 \mathrm{~Hz}$ magnetic field-induced DNA damage in rat lymphocytes," Mutation Research, vol. 483, no. 1-2, pp. 5764, 2001.

[65] B. Yokus, D. U. Cakir, M. Z. Akdag, C. Sert, and N. Mete, "Oxidative DNA damage in rats exposed to extremely low frequency electro magnetic fields," Free Radical Research, vol. 39, no. 3, pp. 317-323, 2005.

[66] M. Zmyślony, J. Palus, J. Jajte, E. Dziubaltowska, and E. Rajkowska, "DNA damage in rat lymphocytes treated in vitro with iron cations and exposed to $7 \mathrm{mT}$ magnetic fields (static or $50 \mathrm{~Hz}$ )," Mutation Research/Fundamental and Molecular Mechanisms of Mutagenesis, vol. 453, no. 1, pp. 89-96, 2000.

[67] G. d'Ambrosio, R. Massa, M. R. Scarfl, and O. Zeni, "Cytogenetic damage in human lymphocytes following GMSK phase modulated microwave exposure," Bioelectromagnetics, vol. 23, no. 1, pp. 7-13, 2002.

[68] J. L. Phillips, O. Ivaschuk, T. Ishida-Jones, R. A. Jones, M. Campbell-Beachler, and W. Haggren, "DNA damage in molt-4 T-lymphoblastoid cells exposed to cellular telephone radiofrequency fields in vitro," Bioelectrochemistry and Bioenergetics, vol. 45, no. 1, pp. 103-110, 1998.

[69] S. Lixia, K. Yao, W. Kaijun et al., "Effects of $1.8 \mathrm{GHz}$ radiofrequency field on DNA damage and expression of heat shock protein 70 in human lens epithelial cells," Mutation Research, vol. 602, no. 1-2, pp. 135-142, 2006.

[70] L.-X. Sun, K. Yao, J.-L. He, D.-Q. Lu, K.-J. Wang, and H.-W. Li, "Effect of acute exposure to microwave from mobile phone on DNA damage and repair of cultured human lens epithelial cells in vitro," Zhonghua Lao Dong Wei Sheng Zhi Ye Bing Za Zhi, vol. 24, no. 8, pp. 465-467, 2006 (Chinese). 
[71] V. Garaj-Vrhovac, G. Gajski, I. Trošić, and I. Pavičić, "Evaluation of basal DNA damage and oxidative stress in Wistar rat leukocytes after exposure to microwave radiation," Toxicology, vol. 259, no. 3, pp. 107-112, 2009.

[72] A. R. Ferreira, T. Knakievicz, M. A. de Bittencourt Pasquali et al., "Ultra high frequency-electromagnetic field irradiation during pregnancy leads to an increase in erythrocytes micronuclei incidence in rat offspring," Life Sciences, vol. 80, no. 1, pp. 43-50, 2006.

[73] J. Luukkonen, P. Hakulinen, J. Mäki-Paakkanen, J. Juutilainen, and J. Naarala, "Enhancement of chemically induced reactive oxygen species production and DNA damage in human SHSY5Y neuroblastoma cells by $872 \mathrm{MHz}$ radiofrequency radiation," Mutation Research, vol. 662, no. 1-2, pp. 54-58, 2009.

[74] A. G. Gandhi, "Genetic damage in mobile phone users: some preliminary findings," Indian Journal of Human Genetics, vol. 11, no. 2, pp. 99-104, 2005.

[75] A. Karinen, S. Heinävaara, R. Nylund, and D. Leszczynski, "Mobile phone radiation might alter protein expression in human skin," BMC Genomics, vol. 9, article 77, 2008.

[76] A. S. Yadav and M. K. Sharma, "Increased frequency of micronucleated exfoliated cells among humans exposed in vivo to mobile telephone radiations," Mutation Research, vol. 650, no. 2, pp. 175-180, 2008.

[77] V. G. Khurana, C. Teo, M. Kundi, L. Hardell, and M. Carlberg, "Cell phones and brain tumors: a review including the longterm epidemiologic data," Surgical Neurology, vol. 72, no. 3, pp. 205-214, 2009.

[78] IARC (International Agency for Research on Cancer), NonIonizing Radiation, Part 1: Static and Extremely Low-Frequency (ELF) Electric and Magnetic Fields, vol. 80 of IARC Monographs on the Evaluation of Carcinogenic Risks to Humans, IARC Press, Lyon, France, 2002.

[79] J. E. Muscat, M. G. Malkin, S. Thompson et al., "Handheld cellular telephone use and risk of brain cancer," Journal of the American Medical Association, vol. 284, no. 23, pp. 3001-3007, 2000.

[80] J. E. Muscat, M. G. Malkin, R. E. Shore et al., "Handheld cellular telephones and risk of acoustic neuroma," Neurology, vol. 58, no. 8, pp. 1304-1306, 2002.

[81] S. J. Hepworth, M. J. Schoemaker, K. R. Muir, A. J. Swerdlow, M. J. A. van Tongeren, and P. A. McKinney, "Mobile phone use and risk of glioma in adults: case-control study," The British Medical Journal, vol. 332, no. 7546, pp. 883-887, 2006.

[82] A. G. Levis, N. Minicuci, P. Ricci, V. Gennaro, and S. Garbisa, "Mobile phones and head tumours: the discrepancies in causeeffect relationships in the epidemiological studies: how do they arise?" Environmental Health, vol. 10, article no. 59, 2011.

[83] M. H. Repacholi, A. Basten, V. Gebski, D. Noonan, J. Finnie, and A. W. Harris, "Lymphomas in E $\mu$-Piml transgenic mice exposed to pulsed $900 \mathrm{MHz}$ electromagnetic fields," Radiation Research, vol. 147, no. 5, pp. 631-640, 1997.

[84] B. W. Wilson, L. E. Anderson, D. I. Hilton, and R. D. Phillips, "Chronic exposure to $60 \mathrm{~Hz}$ electric fields: effects on pineal function in the rat," Bioelectromagnetics, vol. 2, no. 4, pp. 371380, 1981.

[85] A. Lerchl, K. O. Nonaka, K.-A. Stokkan, and R. J. Reiter, "Marked rapid alterations in nocturnal pineal serotonin metabolism in mice and rats exposed to weak intermittent magnetic fields," Biochemical and Biophysical Research Communications, vol. 169, no. 1, pp. 102-108, 1990.
[86] K. Yaga, R. J. Reiter, L. C. Manchester, H. Nieves, S. Jih-Hsing, and C. Li-Dun, "Pineal sensitivity to pulsed static magnetic fields changes during the photoperiod," Brain Research Bulletin, vol. 30, no. 1-2, pp. 153-156, 1993.

[87] D. L. Henshaw and R. J. Reiter, "Do magnetic fields cause increased risk of childhood leukemia via melatonin disruption?" Bioelectromagnetics, vol. 26, no. 7, pp. S86-S97, 2005.

[88] C. V. Bellieni, M. Tei, F. Iacoponi et al., "Is newborn melatonin production influenced by magnetic fields produced by incubators?" Early Human Development, vol. 88, no. 8, pp. 707-710, 2012.

[89] M. El-Helaly and E. Abu-Hashem, "Oxidative stress, melatonin level, and sleep insufficiency among electronic equipment repairers," Indian Journal of Occupational and Environmental Medicine, vol. 14, no. 3, pp. 66-70, 2010.

[90] W. T. Chance, C. J. Grossman, R. Newrock et al., "Effects of electromagnetic fields and gender on neurotransmitters and amino acids in rats," Physiology and Behavior, vol. 58, no. 4, pp. 743-748, 1995.

[91] H. Sedghi, S. Zare, H. Hayatgeibi, S. Alivandi, and A. G. Ebadi, "Effects of $50 \mathrm{~Hz}$ magnetic field on some factors of immune system in the male guinea pigs," American Journal of Immunology, vol. 1, no. 1, pp. 37-41, 2005.

[92] B. J. Youbicier-Simo, F. Boudard, C. Cabaner, and M. Bastide, "Biological effects of continuous exposure of embryos and young chickens to electromagnetic fields emitted by video display units," Bioelectromagnetics, vol. 18, no. 7, pp. 514-523, 1997.

[93] S. M. J. Mortazavi, S. Vazife-Doost, M. Yaghooti, S. Mehdizadeh, and A. Rajaie-Far, "Occupational exposure of dentists to electromagnetic fields produced by magnetostrictive cavitrons alters the serum cortisol level," Journal of Natural Science, Biology and Medicine, vol. 3, no. 1, pp. 60-64, 2012.

[94] J. M. Thompson, F. Stormshak, J. M. Lee Jr., D. L. Hess, and L. Painter, "Cortisol secretion and growth in ewe lambs chronically exposed to electric and magnetic fields of a 60-Hertz 500-kilovolt AC transmission line," Journal of Animal Science, vol. 73, no. 11, pp. 3274-3280, 1995.

[95] J. Batanjac and E. A. Pauncu, "Risk of 50/60 hertz electromagnetic fields in electric utility workers," Facta Universitatis: Medicine and Biology, vol. 10, no. 2, pp. 99-100, 2003.

[96] K. Radon, D. Parera, D.-M. Rose, D. Jung, and L. Vollrath, "No effects of pulsed radio frequency electromagnetic fields on melatonin, cortisol, and selected markers of the immune system in man," Bioelectromagnetics, vol. 22, no. 4, pp. 280-287, 2001.

[97] Y. Djeridane, Y. Touitou, and R. de Seze, "Influence of electromagnetic fields emitted by GSM-900 cellular telephones on the circadian patterns of gonadal, adrenal and pituitary hormones in men," Radiation Research, vol. 169, no. 3, pp. 337-343, 2008.

[98] E. F. Eskander, S. F. Estefan, and A. A. Abd-Rabou, "How does long term exposure to base stations and mobile phones affect human hormone profiles?" Clinical Biochemistry, vol. 45, no. 12, pp. 157-161, 2012.

[99] C. Augner, G. W. Hacker, G. Oberfeld et al., "Effects of exposure to GSM mobile phone base station signals on salivary cortisol, alpha-amylase, and immunoglobulin A," Biomedical and Environmental Sciences, vol. 23, no. 3, pp. 199-207, 2010.

[100] H. A. Shahryar, A. Lotfi, M. B. Ghodsi, and A. R. Karami Bonary, "Effects of $900 \mathrm{MHz}$ electromagnetic fields emitted from a cellular phone on the T3, T4, and cortisol levels in Syrian hamsters," Bulletin of the Veterinary Institute in Pulawy, vol. 53, no. 2, pp. 233-236, 2009. 
[101] H. A. Shahryar, A. R. Lotfi, M. Bahojb, and A. R. Karami, "Effects of electromagnetic fields of cellular phone on cortisol and testosterone hormones rate in Syrian Hamsters (Mesocricetus auratus)," International Journal of Zoological Research, vol. 4, no. 4, pp. 230-233, 2008.

[102] K. Mann, P. Wagner, G. Brunn, F. Hassan, C. Hiemke, and J. Röschke, "Effects of pulsed high-frequency electromagnetic fields on the neuroendocrine system," Neuroendocrinology, vol. 67, no. 2, pp. 139-144, 1998.

[103] K. Vangelova, M. Israel, D. Velkova, and M. Ivanova, "Changes in excretion rates of stress hormones in medical staff exposed to electromagnetic radiation," Environmentalist, vol. 27, no. 4, pp. 551-555, 2007.

[104] K. Vangelova, M. Israel, and S. Mihaylov, "The effect of low level radiofrequency electromagnetic radiation on the excretion rates of stress hormones in operators during 24-hour shifts," Central European Journal of Public Health, vol. 10, no. 1-2, pp. 23-27, 2002.

[105] M. R. Sarookhani, R. M. Asiabanha, A. Safari, V. Zaroushani, and M. Ziaeiha, "The influence of $950 \mathrm{MHz}$ magnetic field (mobile phone radiation) on sex organ and adrenal functions of male rabbits," African Journal of Biochemistry Research, vol. 5, no. 2, pp. 65-68, 2011.

[106] K. Buchner and H. Eger, "Changes of clinically important neurotransmitters under the influence of modulated RF fieldsa long-term study under real-life conditions," Umwelt-MedizinGesellschaft, vol. 24, no. 1, pp. 44-57, 2011.

[107] S. A. Meo, A. M. Al-Drees, S. Husain, M. M. Khan, and M. B. Imran, "Effects of mobile phone radiation on serum testosterone in Wistar albino rats," Saudi Medical Journal, vol. 31, no. 8, pp. 869-873, 2010.

[108] H. Nakamura, H. Nagase, K. Ogino, K. Hatta, and I. Matsuzaki, "Uteroplacental circulatory disturbance mediated by prostaglandin $\mathrm{F}(2 \alpha)$ in rats exposed to microwaves," Reproductive Toxicology, vol. 14, no. 3, pp. 235-240, 2000.

[109] R. De Seze, P. Fabbro-Peray, and L. Miro, "GSM radiocellular telephones do not disturb the secretion of antepituitary hormones in humans," Bioelectromagnetics, vol. 19, no. 5, pp. 271278, 1998.

[110] S. Mortavazi, A. Habib, A. Ganj-Karami, R. Samimi-Doost, A. Pour-Abedi, and A. Babaie, "Alterations in TSH and thyroid hormones following mobile phone use," Oman Medical Journal, vol. 24, no. 4, pp. 274-278, 2009.

[111] S. Ghione, C. Del Seppia, L. Mezzasalma, M. Emdin, and P. Luschi, "Human head exposure to a $37 \mathrm{~Hz}$ electromagnetic field: effects on blood pressure, somatosensory perception, and related parameters," Bioelectromagnetics, vol. 25, no. 3, pp. 167175, 2004.

[112] N. Håkansson, P. Gustavsson, A. Sastre, and B. Floderus, "Occupational exposure to extremely low frequency magnetic fields and mortality from cardiovascular disease," The American Journal of Epidemiology, vol. 158, no. 6, pp. 534-542, 2003.

[113] D. A. Savitz, D. Liao, A. Sastre, R. C. Kleckner, and R. Kavet, "Magnetic field exposure and cardiovascular disease mortality among electric utility workers," American Journal of Epidemiology, vol. 149, no. 2, pp. 135-142, 1999.

[114] M. Zmyślony, A. Bortkiewicz, and H. Aniołczyk, "Evaluation of selected parameters of circulatory system function in various occupational groups of workers exposed to high frequency electromagnetic fields," Medycyna Pracy, vol. 47, no. 1, pp. 9-14, 1996.
[115] A. Bortkiewicz, M. Zmyślony, E. Gadzicka, C. Pałczyński, and S. Szmigielski, "Ambulatory ECG monitoring in workers exposed to electromagnetic fields," Journal of Medical Engineering and Technology, vol. 21, no. 2, pp. 41-46, 1997.

[116] C. V. Bellieni, M. Acampa, M. Maffei et al., "Electromagnetic fields produced by incubators influence heart rate variability in newborns," Archives of Disease in Childhood: Fetal and Neonatal Edition, vol. 93, no. 4, pp. F298-F301, 2008.

[117] D. L. Hayes, P. J. Wang, D. W. Reynolds et al., "Interference with cardiac pacemakers by cellular telephones," The New England Journal of Medicine, vol. 336, no. 21, pp. 1473-1479, 1997.

[118] F. M. Ali, W. S. Mohamed, and M. R. Mohamed, "Effect of $50 \mathrm{~Hz}$, $0.2 \mathrm{mT}$ magnetic fields on RBC properties and heart functions of albino rats," Bioelectromagnetics, vol. 24, no. 8, pp. 535-545, 2003.

[119] S. Shadfar, S. H. Zamzam, M. B. Zendeh, and V. Tabatabaie, "The examination of the effects of electromagnetic fields on heart tissue of rat using optical microscope," Advances in Environmental Biology, vol. 6, no. 7, pp. 1916-1921, 2012.

[120] A. Bortkiewicz, E. Gadzicka, and M. Zmyślony, "Heart rate variability in workers exposed to medium-frequency electromagnetic fields," Journal of the Autonomic Nervous System, vol. 59, no. 3, pp. 91-97, 1996.

[121] K. Vangelova, C. Deyanov, and M. Israel, "Cardiovascular risk in operators under radiofrequency electromagnetic radiation," International Journal of Hygiene and Environmental Health, vol. 209, no. 2, pp. 133-138, 2006.

[122] S. Spichtig, F. Scholkmann, L. Chin, H. Lehmann, and M. Wolf, "Assessment of intermittent UMTS electromagnetic field effects on blood circulation in the human auditory region using a nearinfrared system," Bioelectromagnetics, vol. 33, no. 1, pp. 40-54, 2012.

[123] R. Andrzejak, R. Poreba, M. Poreba et al., "The influence of the call with a mobile phone on heart rate variability parameters in healthy volunteers," Industrial Health, vol. 46, no. 4, pp. 409-417, 2008.

[124] B. Kodavanji, V. S. Mantur, N. A. Kumar, and S. R. Pai, "A pilot study on long-term effects of mobile phone usage on heart rate variability in healthy young adult males," Journal of Clinical and Diagnostic Research, vol. 6, no. 3, pp. 346-349, 2012.

[125] A. H. Alhusseiny, M. S. Al-Nimer, and A. D. Majeed, "Electromagnetic energy radiated from mobile phone alters electrocardiographic records of patients with ischemic heart disease," Annals of Medical and Health Sciences Research, vol. 2, pp. 146151, 2012.

[126] K. C. Nam, S. W. Kim, S. C. Kim, and D. W. Kim, "Effects of RF exposure of teenagers and adults by CDMA cellular phones," Bioelectromagnetics, vol. 27, no. 7, pp. 509-514, 2006.

[127] A. T. Barker, P. R. Jackson, H. Parry, L. A. Coulton, G. G. Cook, and S. M. Wood, "The effect of GSM and TETRA mobile handset signals on blood pressure, catechol levels and heart rate variability," Bioelectromagnetics, vol. 28, no. 6, pp. 433-438, 2007.

[128] K. D. Thorat and V. Shelke, "Effects of mobile phone radiation on heart rate variation in healthy volunteers," Research Journal of Pharmaceutical, Biological and Chemical Sciences, vol. 4, no. 1, pp. 840-845, 2013.

[129] E. Sobel, Z. Davanipour, R. Sulkava et al., "Occupations with exposure to electromagnetic fields: a possible risk factor for Alzheimer's disease," American Journal of Epidemiology, vol. 142, no. 5, pp. 515-524, 1995.

[130] M. Trimmel and E. Schweiger, "Effects of an ELF $(50 \mathrm{~Hz}$, $1 \mathrm{mT}$ ) electromagnetic field (EMF) on concentration in visual 
attention, perception and memory including effects of EMF sensitivity," Toxicology Letters, vol. 96-97, pp. 377-382, 1998.

[131] E. Foroozandeh, H. Ahadi, P. Askari, and M. S. Naeini, "Effects of single, brief exposure to an $8 \mathrm{mT}$ electromagnetic field on avoidance learning in male and female mice," Psychology and Neuroscience, vol. 4, no. 1, 2011.

[132] R. Andel, M. Crowe, M. Feychting et al., "Work-related exposure to extremely low-frequency magnetic fields and dementia: results from the population-based study of dementia in swedish twins," The Journals of Gerontology A: Biological Sciences and Medical Sciences, vol. 65, no. 11, pp. 1220-1227, 2010.

[133] D. Baris, B. G. Armstrong, J. Deadman, and G. Theriault, "A case cohort study of suicide in relation to exposure to electric and magnetic fields among electrical utility workers," Occupational and Environmental Medicine, vol. 53, no. 1, pp. 17-24, 1996.

[134] B. P. Salunke, S. N. Umathe, and J. G. Chavan, "Low frequency magnetic field induces depression by rising nitric oxide levels in the mouse brain," International Journal of Research and Development in Pharmacy and Life Sciences, vol. 2, pp. 439-450, 2013.

[135] K. R. Rajeswari, M. Satyanarayana, P. V. Narayan, and S. Subrahmanyam, "Effect of extremely low frequency magnetic field on serum cholinesterase in humans and animals.," Indian Journal of Experimental Biology, vol. 23, no. 4, pp. 194-197, 1985.

[136] F. S. Prato, J. J. L. Carson, K.-P. Ossenkopp, and M. Kavaliers, "Possible mechanisms by which extremely low frequency magnetic fields affect opioid function," FASEB Journal, vol. 9, no. 9, pp. 807-814, 1995.

[137] L. Zecca, C. Mantegazza, V. Margonato et al., "Biological Effects of Prolonged Exposure to ELF Electromagnetic Fields in Rats: III. $50 \mathrm{~Hz}$ Electromagnetic Fields," Bioelectromagnetics, vol. 19, no. 1, pp. 57-66, 1998.

[138] S. K. Dutta, B. Ghosh, and C. F. Blackman, "Radiofrequency radiation-induced calcium ion efflux enhancement from human and other neuroblastoma cells in culture," Bioelectromagnetics, vol. 10, no. 2, pp. 197-202, 1989.

[139] J. E. H. Tattersall, I. R. Scott, S. J. Wood et al., "Effects of low intensity radiofrequency electromagnetic fields on electrical activity in rat hippocampal slices," Brain Research, vol. 904, no. 1, pp. 43-53, 2001.

[140] F. Ferreri, G. Curcio, P. Pasqualetti, L. De Gennaro, R. Fini, and P. M. Rossini, "Mobile phone emissions and human brain excitability," Annals of Neurology, vol. 60, no. 2, pp. 188-196, 2006.

[141] Y. Fu, C. Wang, J. Wang, Y. Lei, and Y. Ma, "Long-term exposure to extremely low-frequency magnetic fields impairs spatial recognition memory in mice," Clinical and Experimental Pharmacology and Physiology, vol. 35, no. 7, pp. 797-800, 2008.

[142] O. Bas, E. Odaci, S. Kaplan, N. Acer, K. Ucok, and S. Colakoglu, "900 MHz electromagnetic field exposure affects qualitative and quantitative features of hippocampal pyramidal cells in the adult female rat," Brain Research, vol. 1265, pp. 178-185, 2009.

[143] B. Wang and H. Lai, "Acute exposure to pulsed $2450-\mathrm{MHz}$ microwaves affects water-maze performance of rats," Bioelectromagnetics, vol. 21, no. 1, pp. 52-56, 2000.

[144] S. N. Narayanan, R. S. Kumar, B. K. Potu, S. Nayak, P. G. Bhat, and M. Mailankot, "Effect of radio-frequency electromagnetic radiations (RF-EMR) on passive avoidance behaviour and hippocampal morphology in Wistar rats," Upsala Journal of Medical Sciences, vol. 115, no. 2, pp. 91-96, 2010.
[145] G. Abdel-Rassoul, O. A. El-Fateh, M. A. Salem et al., "Neurobehavioral effects among inhabitants around mobile phone base stations," NeuroToxicology, vol. 28, no. 2, pp. 434-440, 2007.

[146] S.-E. Chia, H.-P. Chia, and J.-S. Tan, "Prevalence of headache among handheld cellular telephone users in Singapore: a community study," Environmental Health Perspectives, vol. 108, no. 11, pp. 1059-1062, 2000.

[147] N. D. Volkow, D. Tomasi, G.-J. Wang et al., "Effects of cell phone radiofrequency signal exposure on brain glucose metabolism," The Journal of the American Medical Association, vol. 305, no. 8, pp. 808-813, 2011.

[148] G. Grafström, H. Nittby, A. Brun et al., "Histopathological examinations of rat brains after long-term exposure to GSM900 mobile phone radiation," Brain Research Bulletin, vol. 77, no. 5, pp. 257-263, 2008.

[149] S. Xu, W. Ning, Z. Xu, S. Zhou, H. Chiang, and J. Luo, "Chronic exposure to GSM 1800-MHz microwaves reduces excitatory synaptic activity in cultured hippocampal neurons," Neuroscience Letters, vol. 398, no. 3, pp. 253-257, 2006.

[150] G. Del Vecchio, A. Giuliani, M. Fernandez et al., "Continuous exposure to $900 \mathrm{MHz}$ GSM-modulated EMF alters morphological maturation of neural cells," Neuroscience Letters, vol. 455, no. 3, pp. 173-177, 2009.

[151] K. Yuasa, N. Arai, S. Okabe et al., "Effects of thirty minutes mobile phone use on the human sensory cortex," Clinical Neurophysiology, vol. 117, no. 4, pp. 900-905, 2006.

[152] D. Sokolovic, B. Djindjic, J. Nikolic et al., "Melatonin reduces oxidative stress induced by chronic exposure of microwave radiation from mobile phones in rat brain," Journal of Radiation Research, vol. 49, no. 6, pp. 579-586, 2008.

[153] G. N. De Iuliis, R. J. Newey, B. V. King, and R. J. Aitken, "Mobile phone radiation induces reactive oxygen species production and DNA damage in human spermatozoa In vitro," PLoS ONE, vol. 4, no. 7, Article ID e6446, 2009.

[154] J. Y. Kim, H. T. Kim, K. H. Moon, and H. J. Shin, "Long-term exposure of rats to a $2.45 \mathrm{GHz}$ electromagnetic field: effects on reproductive function," Korean Journal of Urology, vol. 48, no. 12, pp. 1308-1314, 2007.

[155] K. Makker, A. Varghese, N. R. Desai, R. Mouradi, and A. Agarwal, "Cell phones: modern man's nemesis?" Reproductive BioMedicine Online, vol. 18, no. 1, pp. 148-157, 2009.

[156] S. Erpek, M. D. Bilgin, E. Dikicioglu, and A. Karul, "The effects of low frequency electric field in rat testis," Revue de Medecine Veterinaire, vol. 158, no. 4, pp. 206-212, 2007.

[157] J. S. Lee, S. S. Ahn, K. C. Jung, Y.-W. Kim, and S. K. Lee, "Effects of $60 \mathrm{~Hz}$ electro magnetic field exposure on testicular germ cell apoptosis in mice," Asian Journal of Andrology, vol. 6, no. 1, pp. 29-34, 2004.

[158] Y.-W. Kim, H.-S. Kim, J.-S. Lee et al., "Effects of $60 \mathrm{~Hz} 14 \mu \mathrm{T}$ magnetic field on the apoptosis of testicular germ cell in mice," Bioelectromagnetics, vol. 30, no. 1, pp. 66-72, 2009.

[159] B. M. Tenorio, G. C. Jimenez, R. N. Morais, S. M. Torres, R. Albuquerque Nogueira, and V. A. Silva Jr., "Testicular development evaluation in rats exposed to $60 \mathrm{~Hz}$ and $1 \mathrm{mT}$ electromagnetic field," Journal of Applied Toxicology, vol. 31, no. 3, pp. 223-230, 2011.

[160] M. K. Chung, S. J. Lee, Y. B. Kim et al., "Evaluation of spermatogenesis and fertility in F1 male rats after in utero and neonatal exposure to extremely low frequency electromagnetic fields," Asian Journal of Andrology, vol. 7, no. 2, pp. 189-194, 2005. 
[161] M. Davoudi, C. Brossner, and W. Kuber, "The influence of electromagnetic waves on sperm motility," Journal fur Urologie und Urogynakologie, vol. 19, pp. 18-22, 2002.

[162] I. Fejes, Z. Závaczki, J. Szöllosi et al., "Is there a relationship between cell phone use and semen quality?" Archives of Andrology, vol. 51, no. 5, pp. 385-393, 2005.

[163] A. Agarwal, F. Deepinder, R. K. Sharma, G. Ranga, and J. Li, "Effect of cell phone usage on semen analysis in men attending infertility clinic: an observational study," Fertility and Sterility, vol. 89, no. 1, pp. 124-128, 2008.

[164] A. Agarwal, N. R. Desai, K. Makker et al., "Effects of radiofrequency electromagnetic waves (RF-EMW) from cellular phones on human ejaculated semen: an in vitro pilot study," Fertility and Sterility, vol. 92, no. 4, pp. 1318-1325, 2009.

[165] A. A. Otitoloju, I. A. Obe, O. A. Adewale, O. A. Otubanjo, and V. O. Osunkalu, "Preliminary study on the induction of sperm head abnormalities in mice, mus musculus, exposed to radiofrequency radiations from global system for mobile communication base stations," Bulletin of Environmental Contamination and Toxicology, vol. 84, no. 1, pp. 51-54, 2010.

[166] R. J. Aitken, L. E. Bennetts, D. Sawyer, A. M. Wiklendt, and B. $\mathrm{V}$. King, "Impact of radio frequency electromagnetic radiation on DNA integrity in the male germline," International Journal of Andrology, vol. 28, no. 3, pp. 171-179, 2005.

[167] K. K. Kesari, S. Kumar, and J. Behari, "Mobile phone usage and male infertility in wistar rats," Indian Journal of Experimental Biology, vol. 48, no. 10, pp. 987-992, 2010.

[168] M. Mailankot, A. P. Kunnath, H. Jayalekshmi, B. Koduru, and R. Valsalan, "Radio frequency electromagnetic radiation (RF-EMR) from GSM (0.9/1.8GHZ) mobile phones induces oxidative stress and reduces sperm motility in rats," Clinics, vol. 64, no. 6, pp. 561-565, 2009.

[169] E. P. Ribeiro, E. L. Rhoden, M. M. Horn, C. Rhoden, L. P. Lima, and L. Toniolo, "Effects of subchronic exposure to radio frequency from a conventional cellular telephone on testicular function in adult rats," Journal of Urology, vol. 177, no. 1, pp. 395399, 2007.

[170] N. Falzone, C. Huyser, P. Becker, D. Leszczynski, and D. R. Franken, "The effect of pulsed 900-MHz GSM mobile phone radiation on the acrosome reaction, head morphometry and zona binding of human spermatozoa," International Journal of Andrology, vol. 34, no. 1, pp. 20-26, 2011.

[171] D. Weisbrot, H. Lin, L. Ye, M. Blank, and R. Goodman, "Effects of mobile phone radiation on reproduction and development in Drosophila melanogaster," Journal of Cellular Biochemistry, vol. 89, no. 1, pp. 48-55, 2003.

[172] A. Wdowiak, L. Wdowiak, and H. Wiktor, "Evaluation of the effect of using mobile phones on male fertility," Annals of Agricultural and Environmental Medicine, vol. 14, no. 1, pp. 169$172,2007$.

[173] O. Erogul, E. Oztas, I. Yildirim et al., "Effects of electromagnetic radiation from a cellular phone on human sperm motility: an in vitro study," Archives of Medical Research, vol. 37, no. 7, pp. 840843, 2006.

[174] O. J. Møllerløkken and B. E. Moen, "Is fertility reduced among men exposed to radiofrequency fields in the Norwegian Navy?" Bioelectromagnetics, vol. 29, no. 5, pp. 345-352, 2008.

[175] R. Ouellet-Hellstrom and W. F. Stewart, "Miscarriages among female physical therapists who report using radio- and microwave-frequency electromagnetic radiation," American Journal of Epidemiology, vol. 138, no. 10, pp. 775-786, 1993.
[176] J. Han, Z. Cao, X. Liu, W. Zhang, and S. Zhang, "Effect of early pregnancy electromagnetic field exposure on embryo growth ceasing," Journal of hygiene research, vol. 39, no. 3, pp. 349-352, 2010.

[177] A. Gul, H. Çelebi, and S. Uğraş, "The effects of microwave emitted by cellular phones on ovarian follicles in rats," Archives of Gynecology and Obstetrics, vol. 280, no. 5, pp. 729-733, 2009.

[178] Y.-Q. Xu, N.-X. Zheng, B.-H. Li et al., "Female genital toxicities of high-frequency electromagnetic field on rats," Chinese journal of industrial hygiene and occupational diseases, vol. 27, no. 9, pp. 544-548, 2009.

[179] B. Budak, G. G. Budak, G. G. Ozturk, N. B. Muluk, A. Apan, and N. Seyhan, "Effects of extremely low frequency electromagnetic fields on distortion product otoacoustic emissions in rabbits," Auris Nasus Larynx, vol. 36, no. 3, pp. 255-262, 2009.

[180] M. Parazzini, A. R. Brazzale, A. Paglialonga et al., "Effects of GSM cellular phones on human hearing: the European project 'GUARD,' Radiation Research, vol. 168, no. 5, pp. 608-613, 2007.

[181] L. G. Salford, B. Persson, L. Malmgren, and A. Brun, "Téléphonie mobile-effects potentiels sur la santé des ondes électromagnétiques de haute fréquence," in Téléphonie Mobile et Barrière Sang-Cerveau, P. Marco, Ed., pp. 141-152, Emburg, 2001.

[182] M. Parazzini, P. Galloni, M. Piscitelli et al., "Possible combined effects of $900 \mathrm{MHZ}$ continuous-wave electromagnetic fields and gentamicin on the auditory system of rats," Radiation Research, vol. 167, no. 5, pp. 600-605, 2007.

[183] I. Uloziene, V. Uloza, E. Gradauskiene, and V. Saferis, "Assessment of potential effects of the electromagnetic fields of mobile phones on hearing," BMC Public Health, vol. 5, article 39, 2005.

[184] G. Stefanics, L. Kellenyi, F. Molnar, G. Kubinyi, G. Thuroczy, and I. Hernadi, "Short GSM mobile phone exposure does not alter human auditory brainstem response," BMC Public Health, vol. 7, p. 325, 2007.

[185] R. L. Carpenter, "Ocular effects of microwave radiation," Bulletin of the New York Academy of Medicine, vol. 55, no. 11, pp. 1048-1057, 1979.

[186] O. Goldwein and D. J. Aframian, "The influence of handheld mobile phones on human parotid gland secretion," Oral Diseases, vol. 16, no. 2, pp. 146-150, 2010.

[187] A. Spector, "Oxidative stress-induced cataract: mechanism of action," FASEB Journal, vol. 9, no. 12, pp. 1173-1182, 1995.

[188] C. Graham and M. R. Cook, "Human sleep in $60 \mathrm{~Hz}$ magnetic fields," Bioelectromagnetics, vol. 20, pp. 277-283, 1999.

[189] T. Abelin, E. Altpeter, and M. Röösli, "Sleep disturbances in the vicinity of the short-wave broadcast transmitter Schwarzenburg," Somnologie, vol. 9, no. 4, pp. 203-209, 2005.

[190] E.-S. Altpeter, M. Röösli, M. Battaglia, D. Pfluger, C. E. Minder, and T. Abelin, "Effect of short-wave $(6-22 \mathrm{MHz})$ magnetic fields on sleep quality and melatonin cycle in humans: the Schwarzenburg shut-down study," Bioelectromagnetics, vol. 27, no. 2, pp. 142-150, 2006.

[191] C. Wiholm, A. Lowden, L. Hillert et al., "The effects of 884 $\mathrm{MHz}$ GSM wireless communication signals on spatial memory performance-an experimental provocation study," in Proceedings of the Progress in Electromagnetics Research Symposium (PIERS '07), pp. 526-529, Beijing, China, August 2007.

[192] K. Mann and J. Röschke, "Sleep under exposure to highfrequency electromagnetic fields," Sleep Medicine Reviews, vol. 8, no. 2, pp. 95-107, 2004. 
[193] N. M. Maalej and C. A. Belhadj, "External and internal electromagnetic exposures of workers near high voltage power lines," Progress in Electromagnetics Research C, vol. 19, pp. 191-205, 2011.

[194] T. Yoshikawa, M. Tanigawa, T. Tanigawa, A. Imai, H. Hongo, and M. Kondo, "Enhancement of nitric oxide generation by low frequency electromagnetic field," Pathophysiology, vol. 7, no. 2, pp. 131-135, 2000.

[195] M. Yariktas, F. Doner, F. Ozguner, O. Gokalp, H. Dogru, and N. Delibas, "Nitric oxide level in the nasal and sinus mucosa after exposure to electromagnetic field," Otolaryngology-Head and Neck Surgery, vol. 132, no. 5, pp. 713-716, 2005.

[196] I. Meral, H. Mert, N. Mert et al., "Effects of 900-MHz electromagnetic field emitted from cellular phone on brain oxidative stress and some vitamin levels of guinea pigs," Brain Research, vol. 1169, no. 1, pp. 120-124, 2007.

[197] M. K. Irmak, E. Fadillioğlu, M. Güleç, H. Erdoǧan, M. Yağmurca, and Ö. Akyol, "Effects of electromagnetic radiation from a cellular telephone on the oxidant and antioxidant levels in rabbits," Cell Biochemistry and Function, vol. 20, no. 4, pp. 279-283, 2002.

[198] G. Güler, N. Seyhan, and A. Aricioğlu, "Effects of static and 50 $\mathrm{Hz}$ alternating electric fields on superoxide dismutase activity and TBARS levels in guinea pigs," General Physiology and Biophysics, vol. 25, no. 2, pp. 177-193, 2006.

[199] R. J. Reiter, "Static and extremely low frequency electromagnetic field exposure: reported effects on the circadian production of melatonin," Journal of Cellular Biochemistry, vol. 51, no. 4, pp. 394-404, 1993.

[200] C. F. Blackman, "ELF effects on calcium homeostasis," in Extremely Low Frequency Electromagnetic Fields: The Question of Cancer, B. W. Wilson, R. G. Stevens, and L. E. Anderson, Eds., pp. 187-208, Battelle Press, Columbus, Ohio, USA, 1990.

[201] C. F. Blackman, S. G. Benane, D. J. Elliott, D. E. House, and M. M. Pollock, "Influence of electromagnetic fields on the efflux of calcium ions from brain tissue in vitro: a three-model analysis consistent with the frequency response up to $510 \mathrm{~Hz}$," Bioelectromagnetics, vol. 9, no. 3, pp. 215-227, 1988.

[202] C. F. Blackman, L. S. Kinney, D. E. House, and W. T. Joines, "Multiple power-density windows and their possible origin," Bioelectromagnetics, vol. 10, no. 2, pp. 115-128, 1989.

[203] C. F. Blackman, S. G. Benane, and D. E. House, "The influence of temperature during electric- and magnetic-field-induced alteration of calcium-ion release from in vitro brain tissue," Bioelectromagnetics, vol. 12, no. 3, pp. 173-182, 1991.

[204] R. Goodman and M. Blank, "Magnetic field stress induces expression of hsp70," Cell Stress Chaperones, vol. 3, pp. 79-88, 1998.

[205] D. Kültz, "Molecular and evolutionary basis of the cellular stress response," Annual Review of Physiology, vol. 67, pp. 225-257, 2005.

[206] D. de Pomerai, C. Daniells, H. David et al., "Non-thermal heatshock response to microwaves," Nature, vol. 405, no. 6785, pp. 417-418, 2000.

[207] J. Czyz, K. Guan, Q. Zeng et al., "High frequency electromagnetic fields (GSM signals) affect gene expression levels in tumor suppressor p53-deficient embryonic stem cells," Bioelectromagnetics, vol. 25, no. 4, pp. 296-307, 2004.

[208] R. Goodman, M. Blank, H. Lin et al., "Increased levels of hsp70 transcripts induced when cells are exposed to low frequency electromagnetic fields," Bioelectrochemistry and Bioenergetics, vol. 33, no. 2, pp. 115-120, 1994.
[209] J. Friedman, S. Kraus, Y. Hauptman, Y. Schiff, and R. Seger, "Mechanism of short-term ERK activation by electromagnetic fields at mobile phone frequencies," Biochemical Journal, vol. 405, no. 3, pp. 559-568, 2007.

[210] H. Lin, M. Blank, and R. Goodman, "A magnetic field responsive domain in the human HSP70 promoter," Journal of Cellular Biochemistry, vol. 75, pp. 170-176, 1999.

[211] H. Lin, M. Blank, K. Rossol-Haseroth, and R. Goodman, "Regulating genes with electromagnetic response elements," Journal of Cellular Biochemistry, vol. 81, pp. 143-148, 2001.

[212] T. Taira, Y. Negishi, F. Kihara, S. M. M. Iguchi-Ariga, and H. Ariga, "c-myc protein complex binds to two sites in human hsp70 promoter region," Biochimica et Biophysica Acta, vol. 1130, no. 2, pp. 166-174, 1992.

[213] J. Topol, D. M. Ruden, and C. S. Parker, "Sequences required for in vitro transcriptional activation of a Drosophila hsp 70 gene," Cell, vol. 42, no. 2, pp. 527-537, 1985.

[214] G. J. Hook, P. Zhang, I. Lagroye et al., "Measurement of DNA damage and apoptosis in Molt-4 cells after in vitro exposure to radio frequency radiation," Radiation Research, vol. 161, no. 2, pp. 193-200, 2004.

[215] D. Leszczynski, R. Nylund, S. Joenväärä, and J. Reivinen, "Applicability of discovery science approach to determine biological effects of mobile phone radiation," Proteomics, vol. 4, no. 2, pp. 426-431, 2004.

[216] M. Jin, H. Lin, L. Han et al., "Biological and technical variables in myc expression in HL60 cells exposed to $60 \mathrm{~Hz}$ electromagnetic fields," Bioelectrochemistry and Bioenergetics, vol. 44, no. 1, pp. 111-120, 1997.

[217] L. S. Erdreich, M. D. van Kerkhove, C. G. Scrafford et al., "Factors that influence the radiofrequency power output of GSM mobile phones," Radiation Research, vol. 168, no. 2, pp. 253-261, 2007.

[218] S. Sarkar, K. Chandra, R. C. Sawhney, and P. K. Banerjee, "Effect of radiofrequency radiation on biological system," in Topics in Electromagnetic Waves: Devices, Effects and Applications, J. Behari, Ed., pp. 42-73, Anamaya Publishers, New Delhi, India, 2005.

[219] S. Lönn, U. Forssén, P. Vecchia, A. Ahlbom, and M. Feychting, "Output power levels from mobile phones in different geographical areas; implications for exposure assessment," Occupational and Environmental Medicine, vol. 61, no. 9, pp. 769-772, 2004.

[220] A. Christ and N. Kuster, "Differences in RF energy absorption in the heads of adults and children," Bioelectromagnetics, vol. 26, no. 7, pp. S31-S44, 2005.

[221] A. Huss, M. Egger, K. Hug, K. Huwiler-Müntener, and M. Röösli, "Source of funding and results of studies of health effects of mobile phone use: systematic review of experimental studies," Environmental Health Perspectives, vol. 115, no. 1, pp. 1-4, 2007. 

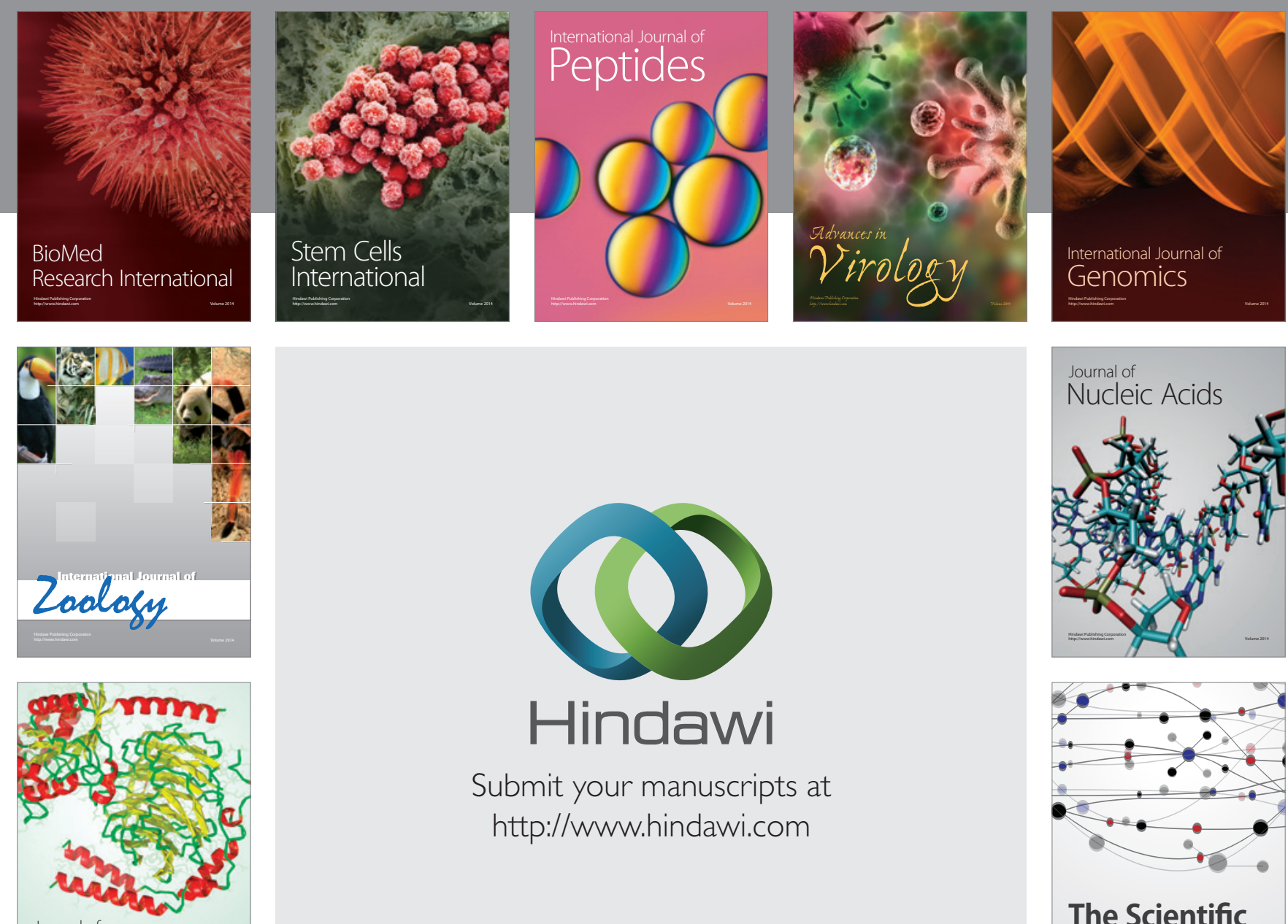

Submit your manuscripts at

http://www.hindawi.com

Journal of
Signal Transduction
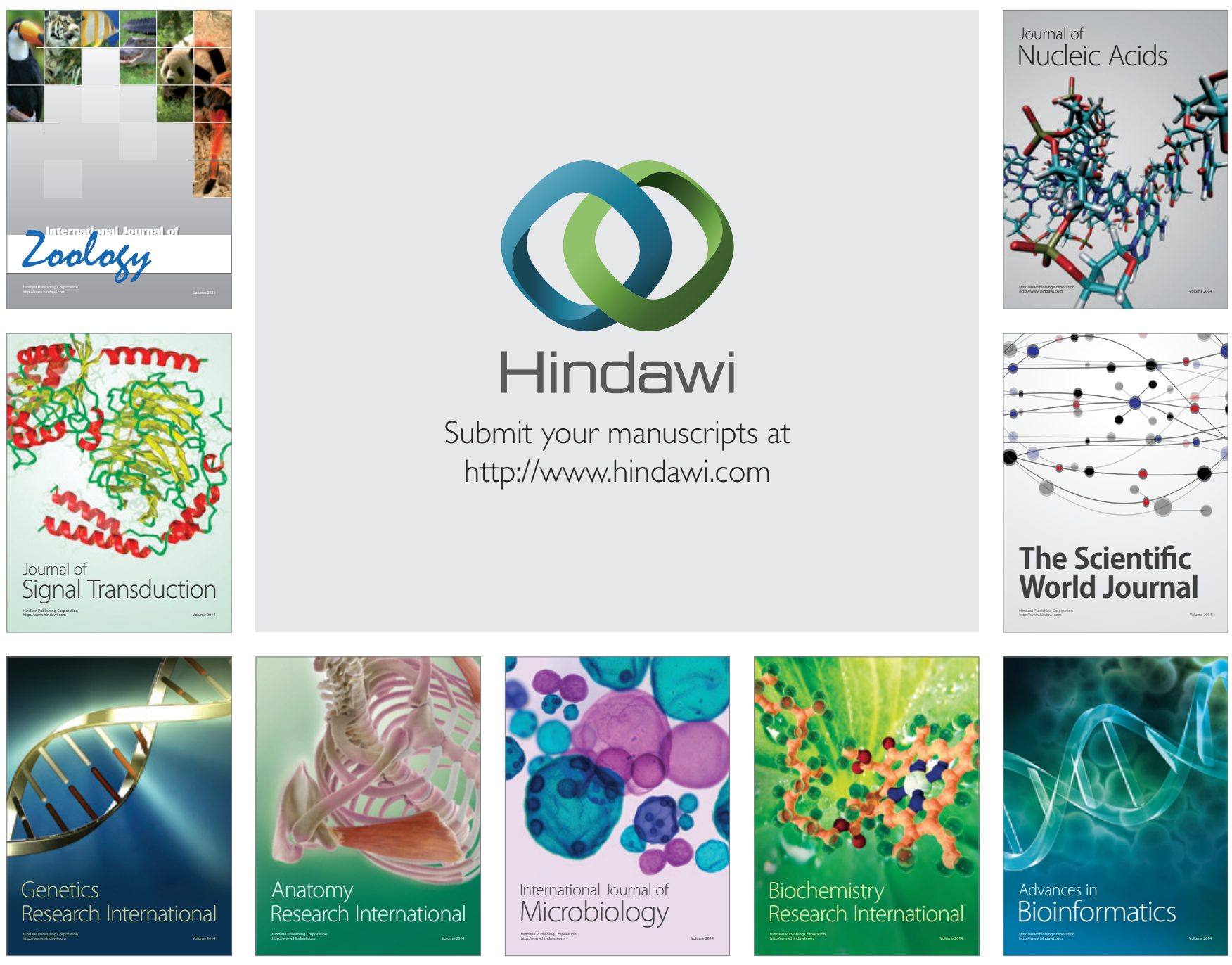

The Scientific World Journal
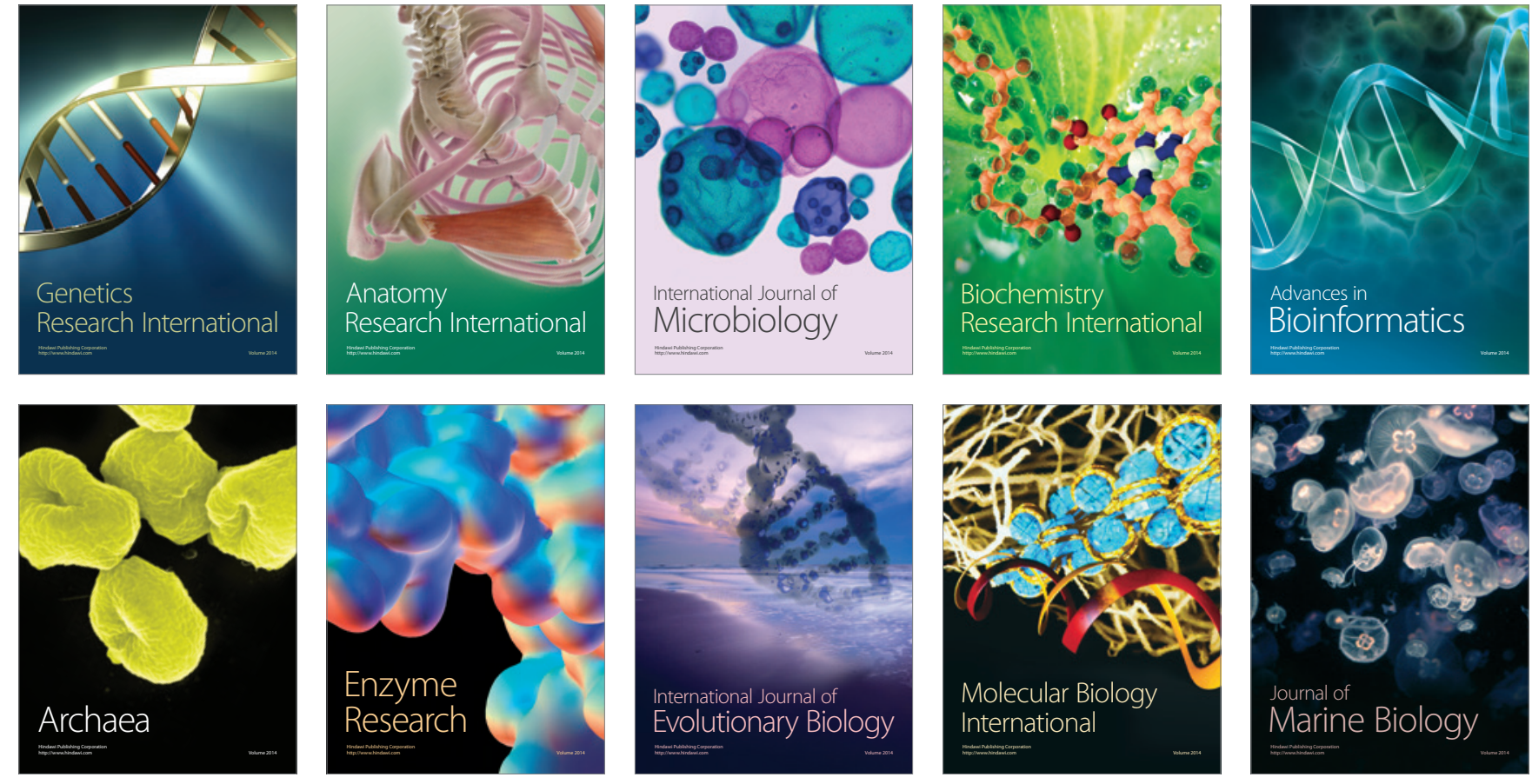